\title{
LA TEORÍA DEL CICLO MONETARIO ENDÓGENO Y LA ECONOMÍA CHINA EN 2011
}

\author{
JESÚS DEL AMO LAMBORENA*
}

Resumen: El presente trabajo tiene por objeto analizar distintas variables de la economía china para tratar de establecer la fase en la que se encuentra la economía china con respecto a la teoría austriaca del ciclo económico. El trabajo consta de tres partes: En la primera se realiza una introducción a la teoría austriaca del ciclo económico, en la segunda se analizan aspectos históricos y estructurales de la economía china, y en la tercera y última se tratan de analizar distintas variables económicas para intentar establecer la posición de la economía china con respecto a su fase de ciclo, para a su vez, tratar de establecer su posible evolución. La principal conclusión del trabajo es que la economía china, a pesar de su enorme tamaño y grado de intervencionismo, no es inmune a las leyes económicas y está sujeta a los mismos avatares que el resto de economías. Si las autoridades chinas siguen con su política intervencionista, las consecuencias serán las mismas que en el resto de economías. Por último, hay que reseñar que la economía china ha demostrado cómo de grandes son las fuerzas de la función empresarial cuando se da libertad económica a la población.

Palabras clave: Economía china, intervencionismo, ciclos económicos, función empresarial.

Clasificación JEL: N15, N27, N45, N65, O53, P11, P32, Y10.

Abstract: The present project has as its objective to analyse different variables of the Chinese Economy in order to establish in which aspect it is in, regarding the Austrian Theory of the economic cycle. The project consists of 3 parts: In the first part an introduction will be conducted on the Austrian theory of

* Licenciado en CC.EE. y EE. por la universidad de Zaragoza y máster en Economía de la Escuela Austriaca por la universidad Rey Juan Carlos de Madrid. Correo: delamo.jesus@gmail.com. Agradezco la dedicación y los útiles comentarios del profesor Philipp Bagus en el desarrollo de este trabajo.

Procesos de Mercado: Revista Europea de Economía Política Vol. IX, n. $\stackrel{-}{1}$, Primavera 2012, pp. 111 a 153 
the economic cycle, in the second part, historical and structural aspects of the chinese economy will be analised, and the third and last part deals with analising the different economic variables to try and establish in which position the chinese economy is in regarding it's cycle stage, and in turn, establish it's possible evolution. Finally we have to underline that the Chinese economy has demonstrated how important the forces of entrepreneurship are when you give economic freedom to the population.

Key words: Chinese economy, interventionism, economic cycles, business function.

JEL Classification: N15, N27, N45, N65, O53, P1 1, P32, Y 10.

\section{I \\ INTRODUCCIÓN}

El presente trabajo tiene como objetivo el estudio de la situación actual de la economía china, utilizando como marco teórico la teoría austriaca del ciclo económico. Desde la incorporación de China al circuito económico mundial en 1978, la economía china ha atravesado varios ciclos con fases expansivas que se han sucedido con otras de recesión.

Desde 2008, la economía China ha entrado en un fuerte crecimiento que no ha ido acompañado de tensiones inflacionistas hasta fechas recientes; en mayo de 2011 el índice de precios al consumo ha subido un $5,5 \%^{1}$ con respecto al año anterior y algunos autores hablan del fin de la burbuja inmobiliaria en China.

En un momento donde todas las economías occidentales han sufrido los peores efectos de la crisis económica provocada por la expansión artificial del crédito facilitada por la FED desde el 2002, China continua siendo el motor de la economía mundial y «la fabrica del mundo», pero esto no implica que su economía quede fuera de las leyes económicas.

${ }^{1}$ http://blogs.wsj.com/chinarealtime/2011/06/14/economists-react-inflationaccelerates-in-may/ 
Aplicando la teoría austriaca del ciclo económico, vamos a tratar de situar el momento actual de la economía China para posteriormente, en función de la posición que ocupe en el ciclo, prever cual podría ser la evolución de la economía china en un futuro próximo.

El trabajo consta de tres partes: La primera parte resume los puntos más importantes de la teoría austriaca del ciclo económico. En la segunda se resumen las características fundamentales de la economía china y en la tercera parte es donde se analizan los datos de la economía china utilizando la teoría austriaca del ciclo económico.

\section{II \\ PRIMERA PARTE: LA TEORÍA AUSTRIACA DEL CICLO ECONÓMICO}

La Teoría Austriaca del Ciclo Económico es la aportación más reconocida de la Escuela Austriaca de Economía. Se basa en la explicación monetaria de los ciclos económicos y sirve como teoría moderna de explicación de las crisis económicas originadas por la expansión del dinero sin respaldo de recursos reales ahorrados.

La teoría del ciclo $^{2}$ demuestra como la expansión monetaria realizada por medio de emisión de créditos sin respaldo de ahorro real, propiciada por los bancos, produce una descoordinación en los procesos de coordinación intertemporal de los agentes que operan en la economía, distorsionando toda la estructura productiva de la sociedad, provocando inicialmente una fase expansiva que desembocará posteriormente, de forma irremediable, en crisis y recesión económica.

Previamente a la explicación de la teoría del ciclo económico es fundamental primeramente conocer los principios esenciales sobre los que se asienta la ciencia económica desde el punto de vista de la Escuela Austriaca, para posteriormente pasar a explicar la teoría del capital, ya que, como afirma el profesor Huerta

2 Para el presente trabajo vamos a seguir las explicaciones del catedrático Huerta de Soto contenidas en su obra Dinero, crédito bancario y ciclos económicos (2011 [1998]). 
de Soto: «La teoría del capital (...) es la clave para entender de que manera la expansión crediticia de la banca distorsiona la estructura productiva real de la economía». ${ }^{3}$

\section{Axiomas básicos de la Escuela Austriaca de Economía ${ }^{4}$}

La ciencia económica se construye en base a razonamientos lógicos deductivos, a partir de unos pocos axiomas que se extraen de la realidad. Estos axiomas son, básicamente, tres: la acción humana, la «ley de utilidad marginal decreciente» y la «ley de preferencia temporal».

\section{a) La acción Humana}

Es el axioma más importante y que sirve de base a todo el razonamiento de la Escuela Austriaca de Economía. ${ }^{5}$ Definimos la acción

\footnotetext{
${ }^{3}$ Huerta de Soto (2011), p. 214.

4 Para una explicación mas exhaustiva ver Huerta de Soto (2004), pp. 160-164 o Huerta de Soto (2011), pp. 213-218.

${ }^{5}$ El enfoque subjetivista es la característica fundamental de la Escuela Austriaca de Economía y lo que la diferencia de otras escuelas como la Escuela Neoclásica basada en el estudio de observaciones de hechos y en la búsqueda de relaciones funcionales. Frente a esto, Huerta de Soto en su artículo sobre la Teoría Austriaca del Ciclo Económico afirma lo siguiente: «El concepto de "acción humana individual" es el principio metodológico sobre el que se construye la teoría económica austriaca. La acción, en este sentido, consta de dos componentes bien diferenciados. Por un lado, se tiene un hecho comprobable del mundo exterior (una piedra que se desploma y mata a alguien); y, por otro, una relación de causa y efecto que tiene siempre su origen en un acto humano de voluntad (la piedra fue arrojada por una persona que la lanzó con la finalidad de producir como resultado dicha muerte). Los economistas ortodoxos se encuentran incómodos con el concepto de "acción humana", ya que, influidos por principios positivistas, prefieren concentrarse tan sólo en lo directamente observable, en una imitación torpe de la labor desarrollada por los científicos de la naturaleza, que esperan les proporcione resultados exactos y precisos. Pero los "austriacos", en contraste con estos pensadores ortodoxos, estiman que la ciencia económica tiene sus métodos propios que no deben forzarse en aras de una demanda de precisión que es absurda, sobre todo si se tiene en cuenta que en Economía, y por trabajarse sobre hombres y no con átomos, tal precisión jamás puede ser obtenida. Además, no se puede tener un verdadero conocimiento de la realidad si, aparte de
} 
humana como toda conducta o comportamiento deliberado. ${ }^{6} \mathrm{El}$ individuo actúa para lograr unos fines que él considera relevantes. A la apreciación psíquica (más o menos intensa) de estos fines se le denomina valor. Por otro parte, se denomina medio a todo aquello que el individuo cree que le servirá para alcanzar sus fines y se denomina utilidad al valor de estos medios. La apreciación de los fines y medios es enteramente subjetiva, es decir, se encuentra en la mente del actor.

\section{b) La ley de utilidad marginal}

El actor clasifica sus fines de forma ordinal, según sus escalas individuales de valor, es decir, de los más apreciados a los menos apreciados. Los medios, por definición, han de ser escasos y por tanto el actor se dedicará primero a conseguir aquellos fines que son para él más valiosos, para después satisfacer aquellos que para él los son menos. En esto consiste la ley de utilidad marginal decreciente.

\section{c) Ley de preferencia temporal}

Por último, entre dos bienes de iguales características, de los que se pueda disponer en momentos distintos de tiempo, el actor siempre preferirá aquel que esté más prontamente disponible. Un aspecto importante es que la acción humana siempre se desarrolla en el tiempo, pero el tiempo no entendido en el sentido analógico, sino como un tiempo subjetivo, que es tal y como lo percibe el actor en el transcurso de la acción. ${ }^{7}$

los meros hechos, no se da entrada a las acciones humanas que los producen, a las escalas de valor individuales que jerarquizan fines y medios y explican, en último extremo, todo humano actuar». Huerta de Soto (2011), p. 161.

6 Huerta de Soto (2005), p. 43.

7 Cualquier aficionado al fútbol conocerá por experiencia propia que rápido pasan los 5 últimos minutos de un partido cuando tu equipo favorito pierde por 1-0 y como son de eternos cuando el resultado es al contrario. Eso es el tiempo en el sentido subjetivo, tal y como es percibido por el actor. 


\section{La teoría austriaca del capital}

a) Capital y bienes de capital

Cuando los individuos establecemos nuestros fines, habitualmente no los conseguimos de forma inmediata. La acción, que transcurre en el tiempo, normalmente necesita de varias etapas para lograr el fin o la meta buscada por el actor que la emprende.

Podemos definir bienes de capital a las etapas intermedias de cada proceso de la acción, subjetivamente consideradas como tales por el actor. ${ }^{8}$ Para poder emprender acciones alejadas en el tiempo, es necesario previamente renunciar a realizar acciones mas inmediatas. Es decir, el actor para alcanzar fines más alejados en el tiempo que requieren de varias etapas, debe renunciar a fines más próximos en el tiempo, es decir, debe ahorrar. El actor tiene que renunciar al consumo inmediato para realizar procesos que tienen más etapas. El motivo por el que el actor emprende este camino más largo es porque espera alcanzar fines más valiosos en el futuro.

El capital es el valor a precios de mercado de los bienes de capital. Es el valor estimado por los actores cuando compran y venden bienes de capital en un mercado libre. ${ }^{9}$

\section{b) La tasa de interés}

Como ya hemos señalado anteriormente, la ley de preferencia temporal establece que a igualdad de circunstancias el individuo siempre prefiere los bienes más inmediatamente disponibles en el tiempo. Ahora bien, este grado de preferencia no es igual en todos los seres humanos. La preferencia temporal de una persona puede ser muy «alta», es decir preferir mucho los bienes presentes con respecto a los futuros, y la de otra persona puede ser más baja; aunque prefiere los bienes presentes es más propensa a renunciar a ellos a cambio de mayor cantidad de bienes en el futuro.

Tenemos por tanto dos actores con preferencias distintas y de sentido contrario y por lo tanto se dan las circunstancias para

\footnotetext{
8 Huerta de Soto (2009), p. 218.

9 Huerta de Soto (2009), p. 226.
} 
que se establezca un mercado donde se intercambien bienes presentes por bienes futuros. Como en todo mercado se establecerá un precio y en el mercado de los bienes presentes por los bienes futuros a este precio se le denomina tipo de interés. Por lo tanto, denominamos tasa o tipo de interés al precio de mercado de los bienes presentes en función de los bienes futuros. ${ }^{10}$

El mercado de bienes presentes por bienes futuros lo forma toda la sociedad, donde ahorradores ofrecen bienes presentes para que los productores puedan disponer de ellos de forma inmediata, incorporándolos a sus procesos productivos y garantizando, de esta manera, un retorno mayor de bienes futuros para la sociedad.

Si la tasa de interés es baja significa que los agentes prefieren mucho los bienes futuros, por lo tanto ahorran y están dispuestos a esperar dichos bienes. Los productores disponen de bienes presentes para completar procesos productivos de larga duración que facilitaran los bienes futuros.

Si por el contrario la tasa de interés es alta, significa que los agentes prefieren el consumo presente, lo cual debe ser tenido en cuenta por los empresarios, no debiendo emprender procesos productivos que se alarguen innecesariamente en el tiempo, ya que los consumidores-ahorradores no están dispuestos a soportar la espera.

La importancia del tipo de interés para la sociedad es por tanto muy grande, ya que sirve para coordinar las decisiones intertemporales de los agentes, entre aquellos que están dispuestos a ahorrar: ahorradores o capitalistas (preferencia temporal baja), y aquellos que necesitan de recursos para ser consumidos de forma inmediata: productores o propietarios de los factores de producción.

\section{c) La estructura productiva}

En las economías modernas, donde se elaboran bienes cada vez más complejos y sofisticados, son necesarias multitud de etapas para la producción de los mismos. Estas etapas componen lo

\footnotetext{
${ }^{10}$ Huerta de Soto (2009), p. 228.
} 
que se denomina la estructura productiva de la economía. Dentro de esta estructura productiva se encuentran las etapas más alejadas del consumo final que son necesarias para que los bienes lleguen al consumidor.

Pensemos en la multitud de etapas que son necesarias para que un vehículo sea adquirido por un consumidor: desde la extracción del mineral de acero que es necesario para su estructura, diseño del vehículo, componentes electrónicos, campañas de marketing, distribución y un largo etcétera hasta que el coche es adquirido por su propietario.

Es importante señalar que, en el complejo entramado que compone una economía moderna, las industrias y trabajadores que realizan bienes de consumo final no son sino apenas una cuarta parte del total de la estructura productiva de la economía. El mayor número de operaciones, transacciones y trabajadores se concentran en las industrias que elaboran bienes de las etapas mas alejadas de los bienes de consumo.

Esto es muy importante, pues los efectos que provoca la expansión crediticia van a producir un mayor impacto en las etapas más alejadas del consumo final, distorsionando así toda la estructura productiva de la sociedad.

\section{Efectos de la expansión crediticia sin respaldo de ahorro real en la estructura productiva}

El ciclo se inicia cuando los bancos empiezan a incrementar la cantidad de dinero disponible en la economía. Estos medios fiduciarios se crean ex-novo, es decir, sin respaldo de recursos reales. El incremento del dinero disponible en la economía, inicia una secuencia de acontecimientos económicos, que de forma esquemática, son los siguientes:

1. CAUSA1: expansión crediticia $(\Uparrow \mathrm{M}) \Rightarrow$ EFECTO1: reducción del tipo de interés $\left(\Downarrow_{\mathrm{r}}\right)$. Los bancos expanden el crédito emitiendo medios fiduciarios sin respaldo de recursos reales. Esto provoca que los bancos se conviertan en oferentes de dinero en el mercado crediticio, lo que provoca la disminución de los tipos 
de interés. Es importante señalar que la tasa de preferencia temporal de la sociedad no ha variado. Son los bancos los que incrementan la oferta de dinero y provocan una disminución artificial del tipo de interés, que se sitúa por debajo del tipo de interés natural que el mercado de bienes presentes por bienes futuros habría fijado.

2. EFECTO1 $\left(\Downarrow_{\mathrm{r}}\right) \Rightarrow$ CAUSA2 (介PIB) estimulación de la actividad económica. Al reducirse los tipos de interés se ven como viables actividades que no lo hubieran sido si los tipos se hubieran mantenido en los niveles de mercado. Esto produce una estimulación artificial de la actividad económica, se inician procesos productivos más largos en el tiempo y se desarrollan las industrias mas alejadas del consumo final: bienes de equipo, construcción, automoción.

3. CAUSA2 ( $(\mathrm{PIB}) \Rightarrow$ EFECTO3 ( $\Uparrow \mathrm{P})$. La estimulación de la actividad económica produce a un aumento en la demanda de materiales de producción y de trabajo. Los precios de los medios de producción y de los salarios crecen y el incremento de los salarios lleva a su vez a un aumento en los precios de los bienes de consumo. ${ }^{11}$ A esto hay que añadir el hecho de que los consumidores no han cambiado su preferencia temporal, por lo que la bajada de los tipos de interés artificial provoca un desincentivo al ahorro y un aumento significativo del consumo.

a) Desajuste intertemporal: Se produce una descoordinación o desajuste entre los agentes económicos. Por un lado, los

11 Huerta de Soto explica cómo el cambio monetario no es neutral. Si se incrementara a la vez todo el dinero existente en la economía, se produciría un aumento de todos los precios en la misma proporción y la estructura productiva no se vería afectada; pero esto nunca es así. Huerta afirma lo siguiente: «Y es que los cambios monetarios jamás son neutrales. Cuando se crea determinada cantidad nueva de dinero, ésta siempre entra en la economía por un punto muy concreto; se gasta primero en determinados bienes y servicios y sólo después, lentamente, se van extendiendo sus efectos por el resto de la estructura productiva. Esto implica que determinados precios se verán afectados antes que otros, modificándose la asignación de recursos como consecuencia de ello. En efecto, gracias a la llegada del nuevo dinero, determinados empresarios que habrían obtenido pérdidas, obtienen beneficios, y muchos trabajadores, que no habrían encontrado trabajo en determinados sectores, se ven fácilmente empleados en los mismos; además, se crean nuevos tipos de negocios, ampliándose las instalaciones ya existentes.» Huerta de Soto (2004), p. 165. 
consumidores no están dispuestos a esperar a que se completen los largos procesos productivos que han emprendido los inversores incentivados por los bajos tipos de interés y por otro, los productores se encuentran con que no disponen de bienes suficientes para completar dichos procesos que han emprendido estimulados por los bajos tipos de interés que se fijan en el mercado y que son financiados con un proceso de expansión crediticia.

b) Alza del precio de las materias primas: Este movimiento ascendente de la economía no puede continuar indefinidamente. El mercado dinámicamente produce una serie de efectos microeconómicos ${ }^{12}$ que dan al traste con todo el proceso de expansión producido por el crédito artificial. Observamos que el dinero es lo único que ha aumentado su cantidad. Sin embargo, ni los medios de producción, ni el trabajo disponible, han seguido el mismo camino; ninguno de los dos elementos ha visto incrementada su cantidad disponible en la economía. Como los empresarios se han lanzado a invertir en procesos productivos más largos, necesitan mas bienes, que no han sido liberados por parte de los consumidores, ya que estos no han renunciado al consumo, no han ahorrado. Los empresarios compiten unos con otros por hacerse con estos bienes $\mathrm{y}$, por tanto, se produce en primer lugar un alza generalizada del coste de los factores de producción.

c) Aumento del precio de los bienes de consumo: Por otro lado los consumidores no han ahorrado, siguen demandando bienes. Así, el consumo tiende a subir más y más, ya que los tipos de interés artificialmente bajos desincentivan aún más el ahorro. Al incrementarse la demanda de bienes de consumo, el precio de los mismos tiende a subir.

d) Recesión: Ante el alza generalizada de precios, tanto de los factores de producción como de los bienes de consumo, los bancos reaccionan subiendo los tipos de interés, incluso por encima de lo que sería su tasa natural, ya que si no frenan la

12 Para estudiar con detalle los efectos microeconómicos ver Huerta de Soto (2009), pp. 289-305. 
inflación todo el sistema económico podría colapsar a causa de la hiperinflación.

e) Quiebras, cierre de empresas y paro: $\mathrm{Al}$ aumentar los tipos de interés, numerosas industrias se encuentran con que las inversiones efectuadas con los tipos artificialmente bajos ya no son rentables, por tanto entran en pérdidas. A esto se une que todos los bienes de capital ven disminuido su valor al aumentar los tipos de interés, lo que produce quiebras de empresas de bienes de capital, como por ejemplo constructoras. Esto provoca impago de créditos y despidos de trabajadores, lo que a su vez provoca una disminución del consumo. La recesión está servida y no cesará hasta que la estructura productiva liquide todas las inversiones erróneas acometidas durante la fase alcista.

\section{III \\ SEGUNDA PARTE: DESCRIPCIÓN DE LA ECONOMÍA CHINA}

China es ya, en 2011, la segunda economía del mundo, por detrás de Estados Unidos y según algunas previsiones será la primera en una década. ${ }^{13}$ Teniendo en cuenta que China abandonó el sistema comunista de planificación central económica en 1978, esto significa que en apenas dos generaciones ha pasado de ser un país atrasado a ser la segunda potencia económica mundial, con 69 empresas dentro de la lista de las 500 más grandes del mundo, elaborada por la revista Fortune ${ }^{14}$ y solo superada por EE.UU. con 133.

Esto no debería ser sorprendente en sí, ya que hasta mitad del siglo XVIII, la civilización china era la más desarrollada del mundo. China retoma su posición en el contexto de la economía

13 Qian Yingyi, reconocido economista de China y decano de la Escuela de Economía y Administración de la Universidad Tsinghua, comentó que China se convertirá en la mayor economía mundial «casi seguramente antes del 2020 en términos de paridad de poder de compra». http://spanish.china.org.cn/economic/txt/2011-07/ 07/content 22941008.htm

14 http://spanish.china.org.cn/economic/txt/2011-07/08/content_22948808.htm 
mundial globalizada en el siglo XXI, y lo hace conquistando el mundo de forma pacífica a través del comercio.

\section{Desarrollo de la economía de mercado en China}

La historia de China se divide en tres grandes periodos (Shenkar 2005):

1. China Imperial: una civilización milenaria de 2000 años de duración.

2. El periodo denominado de «la humillación extranjera» que abarca desde mitad del XVIII y gran parte del XIX.

3. La llegada al poder del comunismo en 1949.

Para nuestro análisis vamos a desarrollar la última etapa de la historia moderna de China.

\section{a) La fundación de la Republica Popular China}

Tras su fundación en 1921, el Partido Comunista de China se convirtió en una de las formaciones políticas más influyentes de China. En 1949, el ejército del partido, denominado Ejército Popular de Liberación, derrotó al Partido Nacionalista Chino o Kuomintang (KMT) en la Guerra Civil China. El líder del PCCh en aquel momento, Mao Zedong, proclamó la nueva República Popular, bajo la dirección del Partido Comunista. ${ }^{15}$

El PCCh implantó un modelo de economía planificada al estilo soviético entre 1953-1957 con el desarrollo del primer plan quinquenal. Este plan se caracterizó por transferencias del sector agrícola al industrial, lo que supuso una reducción de la capacidad de producción del sector agrícola, que apenas llegaba al nivel de subsistencia. (Lemoine 2007)

En 1956, China abandona el modelo de gestión centralizado soviético, se distancia política y económicamente de la URSS y

\footnotetext{
15 http://es.wikipedia.org/wiki/Partido_Comunista_de_China.
} 
entra en un periodo marcado por la convulsión social e ideológica con el denominado «El gran salto adelante» que se inicia en 1958.

Las autoridades chinas encabezadas por Mao Zdenog elaboran un plan que pretende «liberar la energía de las masas, emancipar las mentes, acabar con la burocracia, rechazar los modelos». El «buenismo» aplicado a la economía tiene como resultado una reducción aun mayor de las cosechas y en 1960 el hambre y la desnutrición castigan duramente a la población (Lemoine 2007).

Al gran salto le sucede la Revolución Cultural que se inicia en 1966 y dura hasta 1970. La Revolución Cultural apenas tiene trascendencia en la economía china, principalmente porque la agricultura quedó al margen, si bien tiene un enorme coste en capital humano ya que durante esta etapa se cerraron las universidades que no volvieron a abrir sus puertas hasta 1970 . Wu Xiaobo ${ }^{16}$ señala que después de 10 años de revolución cultural se había destruido todo el funcionamiento del país, incluyendo la habilidad innata de la gente para pensar de forma lúcida y creativa. ${ }^{17}$

b) El despegue del modelo chino:

las reformas de Deng Xiaoping de 1978

La mayoría de los autores señalan el año 1978 como el año de la «fundación» del capitalismo en China y atribuyen el mérito al entonces presidente de China, Deng Xiaoping.

Algunos autores, como Françoise Lemoine, establecen como causa de las reformas económicas a la toma de conciencia por parte de las autoridades chinas del atraso del país: entre 1952 y 1978, el crecimiento económico establece que el incremento anual del PIB por habitante había sido apenas del $2 \%$ y la población china había pasado de 575 a 963 millones.

\footnotetext{
$16 \mathrm{Wu}$ Xiaobo es un reconocido periodista económico chino.

17 Este es uno de los efectos señalados por Huerta de Soto al enunciar el teorema de la imposibilidad del socialismo. El socialismo es el verdadero opio del pueblo que cortocircuita la innata perspicacia humana. Es por tanto la demostración del carácter anti-humano del socialismo.
} 
A esto se le unió que la brecha entre China y la primera generación de nuevas economías que surge en Asia se hizo mas profunda (Taiwán, Hong-Kong, Corea del Sur y Singapur experimentaron un crecimiento vertiginoso en su producción y nivel de vida con tasas de crecimiento del PIB por habitante del 6\%).

En 1978, el Comité Central del Partido Comunista da luz verde a la descolectivización agrícola. Se restablece el beneficio como criterio de gestión de las empresas y las primas de productividad para los trabajadores (Lemoine 2007). Podemos afirmar que China abandonó el modelo comunista y avanzó por la senda de la economía capitalista, caracterizada por la eliminación de la coacción en las relaciones humanas de carácter económico, coacción que constituye la seña de identidad del socialismo. ${ }^{18}$

Durante los años de Mao Zedong se colectivizó toda la actividad agraria de China, se establecieron explotaciones comunitarias y los agricultores estaban sujetos a ellas al modo de los vasallos feudales de la edad media europea. La productividad de estas explotaciones era bajísima y apenas llegaban los agricultores al umbral de subsistencia.

Podemos pensar que en 1978 el gobierno chino rectificó e introdujo la "propiedad privada», si no de la tierra, si al menos de su producción. Pero como ocurre en la mayoría de las ocasiones, los verdaderos cambios, los que modifican el curso de la historia, no se producen en los parlamentos o en las reuniones de los partidos gobernantes.

El caso de la agricultura China, y su abandono del sistema de explotación colectivo maoísta denominado sistema Da-guo-fan, ${ }^{19}$ no se debió a las deliberaciones del PCCh, sino a un grupo de veintiún pobres y harapientos agricultores "pieles-amarillas» que se reunieron en secreto en una remota aldea del distrito de Fengyang

\footnotetext{
18 El comunismo es el grado máximo de socialismo o coacción institucional. En el comunismo la coacción llega hasta los medios de producción que no pueden ser de propiedad privada, con lo que la coacción estatal hacia el individuo antes las decisiones económicas es de grado máximo. Ver Huerta de Soto (2005).

19 Conocido como sistema de gran olla. Bajo este sistema, cada uno recibía la misma cantidad de alimento con independencia de los beneficios que creara su trabajo. Todos comían de la misma «gran olla» del Estado. Xiaobo (2008).
} 
y juraron en un documento, que sellaron con sus huellas digitales, que preferirían ir a la cárcel o ser ejecutados antes de seguir bajo el sistema de Da-guo-fan.

Procedieron a dividir sus tierras y a cultivarlas cada uno por separado, comprometiéndose a entregar la parte que marcaba el Estado, quedándose con el resto de la producción. La cosecha de 1979 fue record. Este sistema denominado «Da-bao-gan», o «sistema de responsabilidad contractual personal», ha sido considerado como el principal desencadenante de los grandes cambios en los pueblos de toda China (Xiaobo 2008).

Una vez mas se demuestra como el individuo es capaz, en un entorno de libertad, de superar todas las dificultades y como el ejercicio sin coacción de la función empresarial es la clave para el desarrollo y prosperidad de la humanidad. Eso es válido tanto para un bróker de Wall-Street como para un agricultor de una remota aldea china.

(i) El avance del modelo de «socialismo de mercado chino»: 1984-1991

El avance del capitalismo en China, como todos los procesos económicos, no ha sido lineal. Superada la primera etapa que va de 1978 a 1984, donde las reformas fueron ambiguas y frágiles, la economía china entró en un periodo marcado por la aplicación de una economía con un doble sistema de precios: un sistema regulado de precios de los productos para las empresas estatales y otro libre para el resto de empresas «privadas» que habían ido surgiendo a la luz de las reformas.

Pronto el sistema mostró numerosos fallos y se produjeron grandes distorsiones entre ambos sistemas de precios que fueron el caldo de cultivo para que muchos se aprovecharan de la diferencia entre ambos precios. Así, muchos funcionarios que tenían acceso a las materias primas, compraban a precios oficiales y vendían a precios de mercado, obteniendo con ello cuantiosos beneficios. Esto provocó tensiones entre la población cuyo efecto mas notorio a nivel mundial fueron las revueltas de la plaza de Tian'anmen en junio de 1989. 
Xiaobo señala como un motor del cambio hacia la liberalización de la economía china al premio nobel Friedrich A. Hayek, que en 1988 publicó «La fatal arrogancia». En palabras de Xiabo: «El libro de Hayek proporcionó una munición teórica muy oportuna para los países capitalistas occidentales. Y en algunos círculos de China era considerado como un auténtico tesoro» (Xiaobo 2008).

El gobierno decidió abandonar el sistema de precios regulados en 1989, lo que en un primer momento provocó enormes tensiones inflacionistas. La oficina Estatal de Control de precios anotó en su Anuario de precios de China que los precios subieron mas deprisa que en ningún año desde 1950, año en que la inflación fue considerable. Los precios subieron un 95\% en el IPC de 383 productos utilizados por el Estado para calcular los precios de mercado (Xiaobo 2008).

Pero en contra de lo que pensaban muchos economistas occidentales, China no colapsó, sino que transformó su economía recalentada en otra con un crecimiento más estable, sembrando las semillas de la gran apertura posterior. De 1990 a 1991, el Estado decide retomar las riendas y congelar las reformas. Sin embargo el cambio iniciado demuestra ser irreversible (Lemoine 2007).

\section{c) La apertura al mundo: 1992}

En enero de 1992, Deng Xiaoping, durante una visita a las ciudades industriales del sur de China, da salida oficial a las nuevas reformas y, en otoño, el XIV congreso del Partido les asigna un nuevo objetivo: la «economía socialista de mercado» (Lemoine 2007).

Se produce la liberalización definitiva de los precios y en 1992, ya el $80 \%$ del comercio mayorista y minorista se realiza a precios libres. En noviembre de 1993 el Comité Central del Partido relanza la reforma de las empresas estatales y prevé la diversificación de las formas de propiedad. Se impulsan las inversiones extranjeras. En 1994 se introducen reformas para establecer un verdadero sistema bancario, fiscal y un régimen de tipos de cambio con el yuan. 
En diciembre de 2001 China ingresa en la Organización Mundial del Comercio (OMC), lo cual abre aún más a China a la competencia internacional, lo que impulsa la dinámica, ya irreversible, de los cambios.

\section{La economía china de mercado}

La rápida evolución de la economía china hacia la economía de mercado, ha provocado enormes cambios en los sectores agrarios chinos, en el sector industrial, en el comercio e inversiones, en el sistema fiscal, y en el sistema bancario. Vamos a ver de forma resumida los principales cambios en cada sector.

\section{a) La transformación agraria}

Como hemos comentado anteriormente, en 1978 se produce el primer cambio significativo en la economía china con la aparición de los contratos de responsabilidad entre las administraciones rurales y las familias o grupos de familias de agricultores. Como señala Lemoine: «A finales de 1984 más del 95\% de las familias campesinas trabajaban de acuerdo a estos contratos».

A su vez el Estado incrementa los precios de compra de los artículos a los agricultores, sin trasladar estas subidas a los consumidores. En 1982, el Estado elimina el monopolio sobre los cereales. A partir de 1983, las comunas populares se desmantelan. Todos estos cambios impulsaron la productividad y la diversificación de los cultivos.

No obstante, a partir de mediados de $\operatorname{los} 80$, frente a las mejoras del nivel de vida experimentadas por los campesinos desde 1978, estas mejoras se estancan e incluso empeoran comparadas con las ciudades.

Los principales problemas del campo chino son la falta de inversión en infraestructuras, la falta de propiedad privada que impide a las familias chinas capitalizarse, la falta de conexión entre muchas zonas rurales y las zonas urbanas más ricas y la sobrepoblación rural. 
Lemoine señala que «a partir de 2004 los programas del gobierno, y especialmente el plan 2006-2010, anuncian prioridades a favor de la producción agrícola y de la renta de los campesinos».

\section{b) La transformación de las empresas públicas}

Xiaobo señala que «la baja eficiencia siempre había supuesto un problema en las empresas públicas en China». Este autor apunta a la inexistencia de responsabilidades como causa del problema: «Todo el mundo era jefe y al mismo tiempo nadie asumía responsabilidades» (Xiaobo 2008).

En este marco, comienzan las reformas de 1978. Uno de sus objetivos fue dotar de más independencia a las empresas públicas en la toma de decisiones, pero también en la asunción de responsabilidades.

Poco a poco las empresas del Estado van conservando, para su propia gestión, parte de sus beneficios. En 1984 se produce la reforma fiscal por la cual, los ingresos de los presupuestos del Estado son sustituidos por un impuesto progresivo sobre los beneficios (Lemoine 2007).

Si bien estas reformas supusieron un avance, en los años 90 las empresas públicas no resistieron la competencia que les proporcionó el nuevo marco abierto de la economía china. En 1998, casi la mitad de las empresas del Estado dieron pérdidas.

El camino emprendido por las autoridades chinas puede resumirse en el slogan: «El pueblo dentro, el Estado fuera». El Estado ha salido de muchos sectores industriales, conservando la participación en las empresas, pero aplicando criterios de gestión modernos y basados en la rentabilidad y el beneficio.

Esta política ha permitido que multinacionales, empresas privadas locales y empresas públicas se hayan desarrollado y actualmente estén a la cabeza mundial en la producción de electrodomésticos, juguetes y textil. 


\section{c) El sistema bancario}

Hasta 1979 el sistema bancario chino contaba con un solo banco, el Banco del Pueblo de China (BPC), que actuaba como Banco Central y único Banco Comercial. Tras la separación de ambas funciones, el BPC siguió encargado de la política monetaria y la regulación bancaria y el cuerpo principal del sistema bancario chino pasó a estar integrado por tres grupos de bancos.

El primer grupo está formado por los bancos estatales, integrado por cuatro grandes bancos públicos especializados en la concesión de créditos, cada uno de ellos en un área considerada clave para el desarrollo económico del país que abarca el sector agrícola, el industrial, el comercio exterior y el sector de la construcción. Los mismos son:

1. Banco de China: especializado en transacciones en moneda extranjera y financiación comercial.

2. Banco de la Construcción de China: su principal actividad es la evaluación, gestión y financiación de proyectos de infraestructura a gran escala y también el desarrollo inmobiliario urbano.

3. Banco Industrial y Comercial de China: es el mayor banco de China. Es el principal proveedor de créditos para las economías urbanas del país, a través de préstamos a corto plazo para capital circulante de empresas y proyectos de infraestructura e inmobiliarios.

4. Banco Agrícola de China: especializado en financiación del sector agrícola y servicios de banca mayorista-minorista para los agricultores y otras instituciones y empresas rurales.

El segundo grupo está integrado por los bancos comerciales, que aún siendo estatales, excepto uno de ellos, su tamaño financiero es menor. Son los siguientes:

1. Bank of Communication.

2. China Everbright Bank.

3. CITIC Industrial Bank.

4. Shanghai Pudond Development Bank. 
5. Shenzhen Development Bank.

6. China Minsheng Bank (privado).

7. Hua Xia Bank.

Estos bancos, en general, están más saneados en términos de calidad de activos y beneficios, con una cantidad menor de préstamos de difícil recuperación.

En un tercer y último grupo están los bancos extranjeros, que hasta el momento son 64 procedentes de 19 naciones con 192 oficinas bancarias en el país, de las cuales, 88 han obtenido autorización para llevar a cabo negocios en yuanes. ${ }^{20}$

Para Lemoine, la necesidad de intermediación surgida del rápido desarrollo de la economía china es el origen del sistema financiero chino. Así señala: «En el curso de los años 80, bajo el efecto de la monetarización de la economía y del incremento de las rentas, el ahorro de las familias aumentó rápidamente, y sus depósitos bancarios pasaron del 5\% del PIB en 1978 al 37\% en 1990 $y$ al 87 por 100 en 2004» (Lemoine 2007).

La peculiaridad del sistema financiero chino radica en que si bien las cuentas públicas chinas están saneadas, el sistema financiero chino presenta muchos créditos de dudoso cobro procedentes de préstamos a empresas estatales con dificultades. Lemoine señala que entre 1998 y 2005 el Estado destinó un 30\% del PIB (430.000 millones de USD) a la recapitalización de los bancos y a librarlos de sus créditos dudosos.

El mercado bursátil chino es de reciente creación. En 1991 se creo la bolsa de Shenzen y en 1994, la de Shanghai. El aumento de la capitalización ha sido enorme, pero llena de sobresaltos. Las bolsas chinas han sido propensas a las operaciones especulativas sin respaldo de activos reales.

Pero el balance es positivo, como señala Xiaobo: «Los problemas de la bolsa pusieron al descubierto la juventud y la inmadurez de los mercados de capitales de China. Sin embargo, en general, el mercado también permitió una economía mas dinámica y los empresarios pudieron ejercer toda su creatividad».

${ }^{20}$ Rodríguez (2007). 


\section{d) Estructuras económicas}

No es posible realizar un trabajo sobre China sin indicar que China presenta una población de 1.300 millones de personas, aproximadamente una cuarta parte de la población mundial. ${ }^{21}$

China tiene una extensión de 9,6 millones de kilómetros cuadrados, casi como EE.UU. Aproximadamente un $80 \%$ de la población vive en menos de la mitad del territorio y la densidad de población varia de menos de 10 habitantes por kilómetro cuadrado en las provincias occidentales de Xinjing y Qinhai, a más de 500 en la provincia central de Henan y en las provincias litorales de Jiangsu y Sahndong (Lemoine 2007).

MAPA 1

MAPA DE CHINA

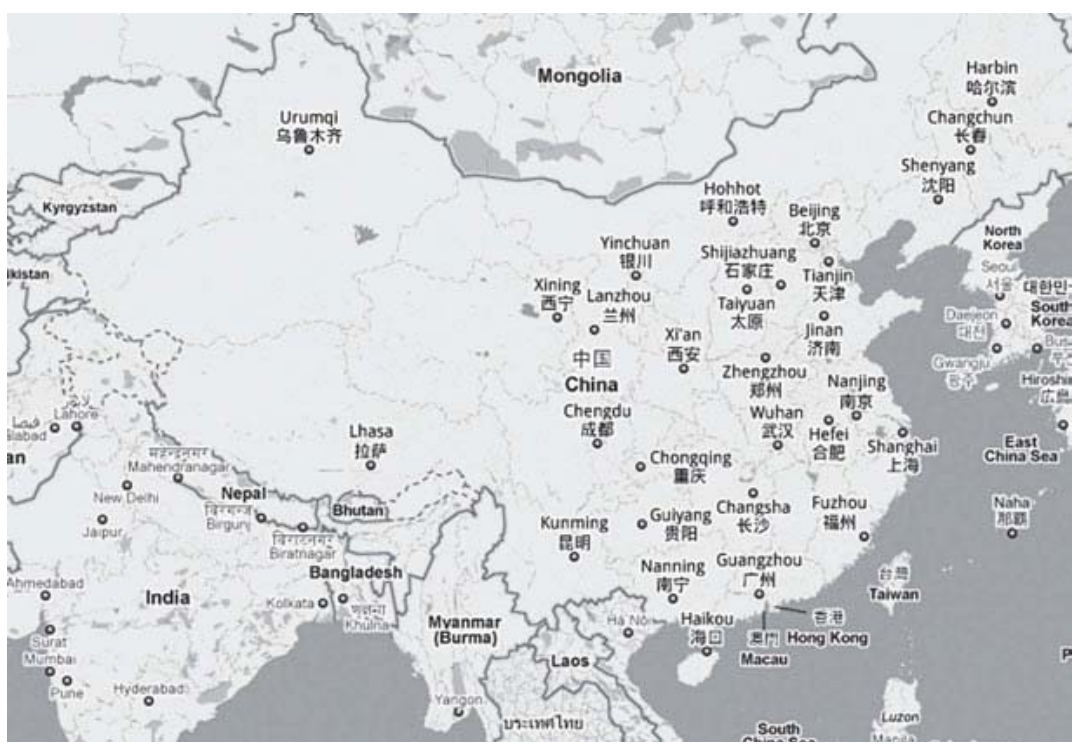

Fuente: googlemaps.

${ }^{21}$ (SPANISH.CHINA.ORG.CN) —-La proporción de chinos en la población mundial ha caído del 22 al 19 por ciento en los últimos 30 años. 
Actualmente China presenta una baja tasa de natalidad (13 $\mathrm{x}$ mil) y de mortalidad (6,5 x mil). La esperanza de vida está en los 72 años, la tasa de alfabetización declarada es del $90 \%$ y la tasa de mortalidad infantil (30 por mil) muestra un nivel de desarrollo superior a la India.

Con respecto al nivel de vida, en 2003 una décima parte de la población seguía subalimentada y un $15 \%$ vivía por debajo del nivel de la pobreza. Sin embargo, el número de personas afectadas por la extrema pobreza ha disminuido a la mitad en diez años. Se estima que más de 400 millones de personas han podido salir de la pobreza gracias al capitalismo chino. Con respecto al PIB, este ha aumentado una media del 9,5\% anual entre 1980 y 2009 (Gráfico 1).

GRÁFICO 1

CRECIMIENTO PORCENTUAL DEL PIB

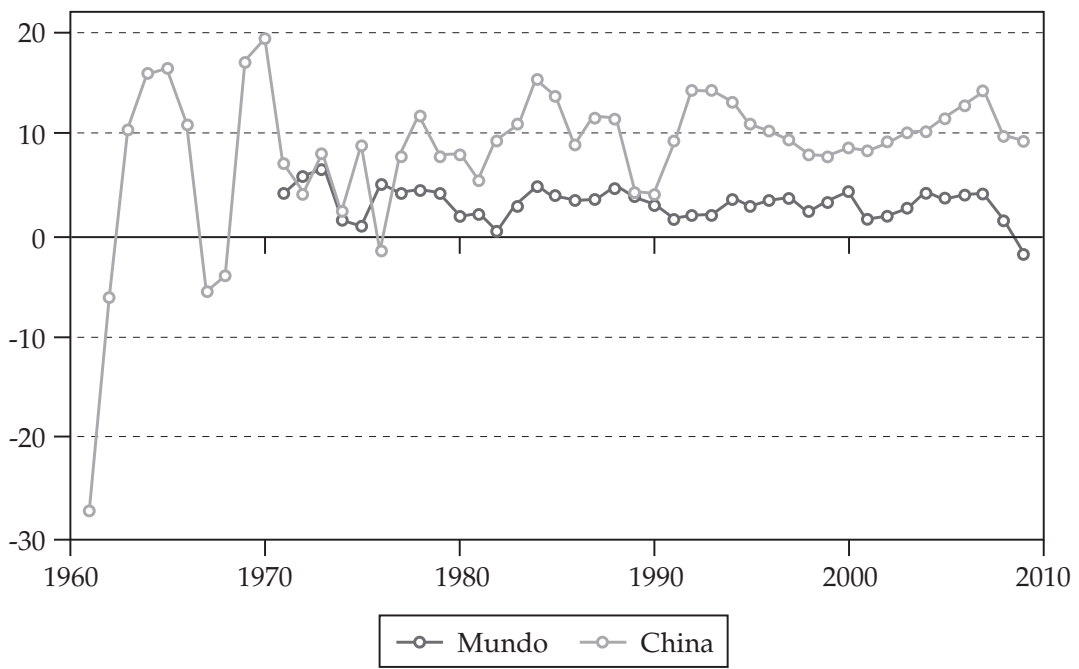

Nota: Tasa de crecimiento anual porcentual del PIB a precios de mercado en moneda local, a precios constantes. Los agregados están expresados en dólares de los Estados Unidos a precios constantes del año 2000. El PIB es la suma del valor agregado bruto de todos.

Fuente: Datos sobre las cuentas nacionales del Banco Mundial y archivos de datos sobre cuentas nacionales de la OCDE. Fuentes Indicadores del desarrollo mundial. 
China produce en la actualidad el 5\% del PIB mundial. Actualmente es la segunda economía mundial. Con respecto al PIB, este ha aumentado una media del 9,5\% anual entre 1980 y 2009 (Gráfico 2).

La renta per cápita de China en 2009 fue de 6.675 USD, ${ }^{22}$ lejos de países desarrollados, como EE.UU. (46.000 aprox.) o España (32.000). En términos de renta per-cápita, China aún es un país subdesarrollado.

Esto no puede restar mérito al camino emprendido por la economía china, ya que la renta per cápita en 1960 era de 400 USD

GRÁFICO 2

PRODUCTO INTERIOR BRUTO

(PIB en dólares estadounidenses corrientes.

No se ajusta a la inflación)

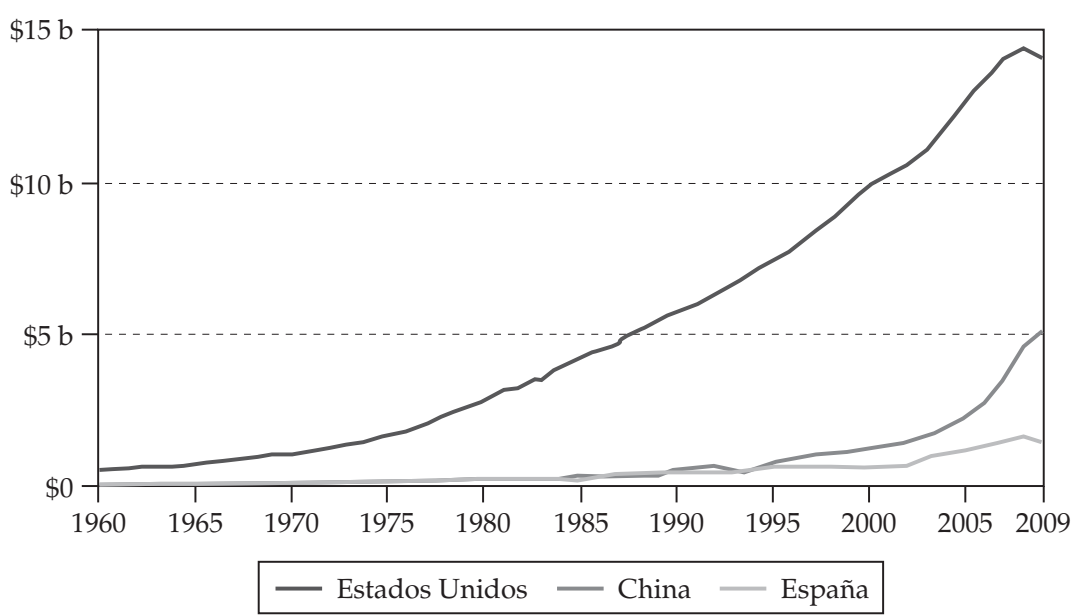

Fuente: Banco Mundial. Indicadores del desarrollo mundial. Última actualización en 26 de abril de 2011.

22 Fuente: Banco Mundial. Según su producto interno bruto (PIB) a valores de paridad de poder adquisitivo (PPA) per cápita significando la suma de todos los bienes y servicios finales producidos por un país en un año, dividido por la población promedio del mismo año. http:/ / es.wikipedia.org/wiki/Anexo:Pa\%C3\%ADses_por_ PIB_(PPA)_per_cápita. 
frente a los 4.900 de Japón (Japón presenta en 2009 una renta de 32.443 USD).

China es el primer productor mundial de trigo y de arroz y el segundo de maíz, por detrás de EE.UU. El rendimiento de la agricultura china es elevado. La ganadería ha registrado un aumento considerable, pasando de 19 a 70 millones de producción de toneladas de carne desde 1978 a 2006.

El carbón es la principal fuente de energía en China, siendo el primer productor y consumidor mundial de carbón. El carbón supone el $60 \%$ del consumo primario de energía. El petróleo supone el $30 \%$ y gana terreno. La madera todavía representa un 16\% del consumo total de energía. El resto se completa con gas, hidroelectricidad y energía nuclear.

La industria China se compone de alrededor 220.000 empresas, 2000 grandes, 22.000 medianas y 200.000 pequeñas, que se reparten la producción total en una proporción similar.

China era en 2005 el tercer productor mundial de coches, por detrás de EE.UU. y Japón. La notoriedad de la empresas del Estado aún es importante en la economía china, ostentando monopolios como tabaco, petróleo, petroquímicas, siderurgia y carbón.

La presencia de empresas extranjeras en China es notable pues todas las grandes multinacionales están presentes en el mercado chino. En la actualidad, la producción industrial de las empresas con capital extranjero se reparte casi por igual entre exportación y comercialización en el mercado chino.

Con respecto a la tecnología, China ha hecho grandes avances en el campo científico y técnico estos últimos años, pero sigue estando muy retrasada con respecto al resto de países industrializados. China solo aporta el 0,3\% de las patentes a nivel mundial (Lemoine 2007) (Gráfico 3).

La balanza de pagos desde los primeros años 90 es regularmente excedentaria. Sus ingresos corrientes también son superiores a sus gastos, por lo que China obtiene un ahorro neto. El doble excedente de la cuenta corriente y de la cuenta de capital se traduce en entrada neta de divisas en el país, lo que lleva a acumular reservas de cambio. En 2006 las reservas de dólares superaron los 900.000 millones de dólares. La mayor parte de estas reservas 
GRÁFICO 3

SALDO EN CUENTA CORRIENTE

(Balanza de pagos US\$ a precios actuales)

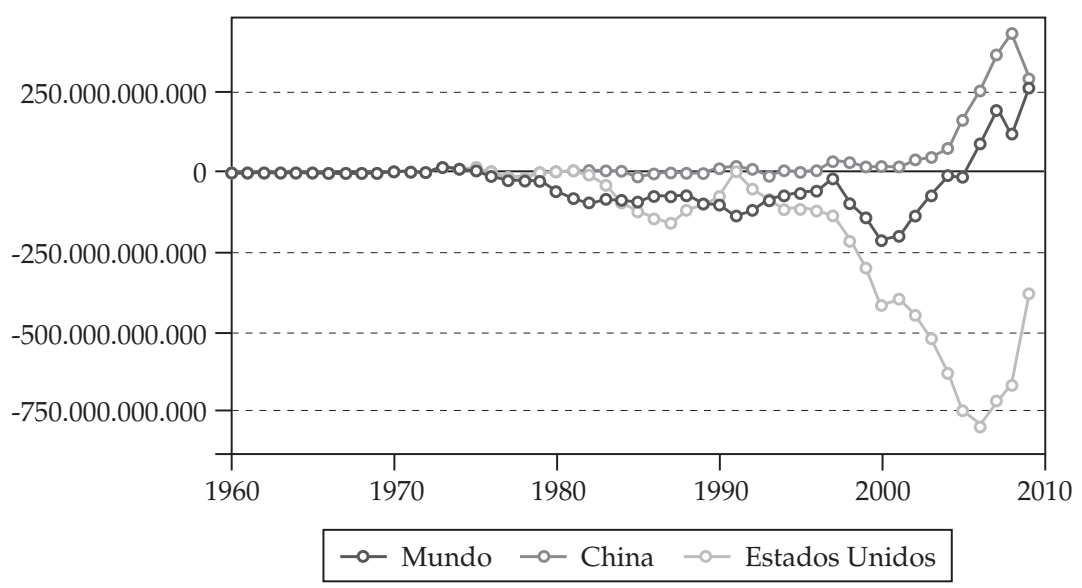

Nota: El saldo en cuenta corriente es la suma de las exportaciones netas de bienes, servicios, ingresos netos y transferencias corrientes netas. Los datos se expresan en dólares de los Estados Unidos a precios corrientes.

Fuente: FMI, Anuario de Estadísticas de Balanza de Pagos y archivos de datos.

están colocadas en bonos del tesoro americano, lo que convierte a China en el segundo acreedor de EE.UU. por detrás de Japón (Lemoine 2007).

IV

TERCERA PARTE:

TEORÍA ENDÓGENA DEL CICLO MONETARIO ENDÓGENO: EL CASO DE CHINA

En 1998 se produce la liberalización del sector inmobiliario en China como respuesta de las autoridades chinas a la crisis financiera que sacudió a las economías del sudeste asiático. Las autoridades con ánimos de impulsar la demanda interna comenzaron a tomar medidas monetarias para manipular el ciclo. 


\section{Oferta monetaria}

La evolución de la oferta monetaria en China desde 1994 la podemos observar en los Gráficos 4, 5 y 6.

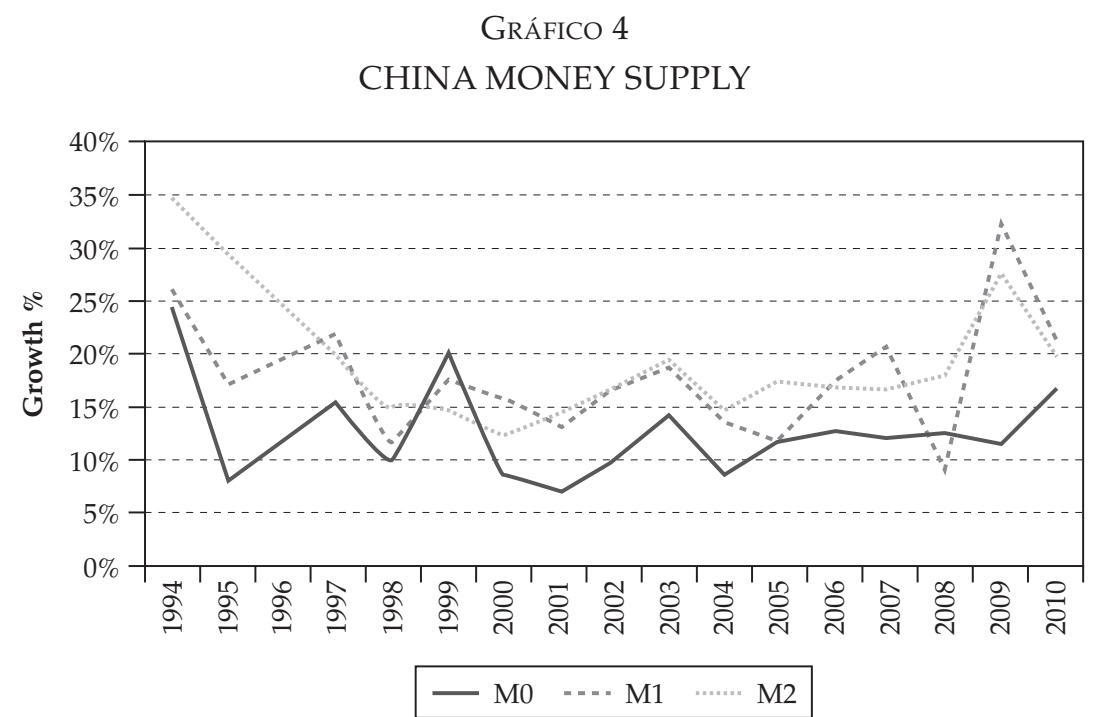

Fuente: Dragonomics

Crecimiento del dinero en $\%$ anual de China y USA. La oferta de dinero en China ha experimentado un incremento sostenido desde el año 2000 y se ha acelerado el crecimiento desde 2009 (Gráfico 7).

\section{Ahorro}

La economía china presenta una particularidad que no tienen otras economías y es la baja tasa de preferencia temporal de los ciudadanos chinos que los hace muy ahorradores. Es una economía con ahorro disponible y con entrada neta de divisas. Lo podemos ver en el gráfico del ahorro bruto interno. Para mayor claridad lo comparamos con el de EE.UU. (Gráfico 8). 
GRÁFICO 5

CHINA MONEY SUPPLY

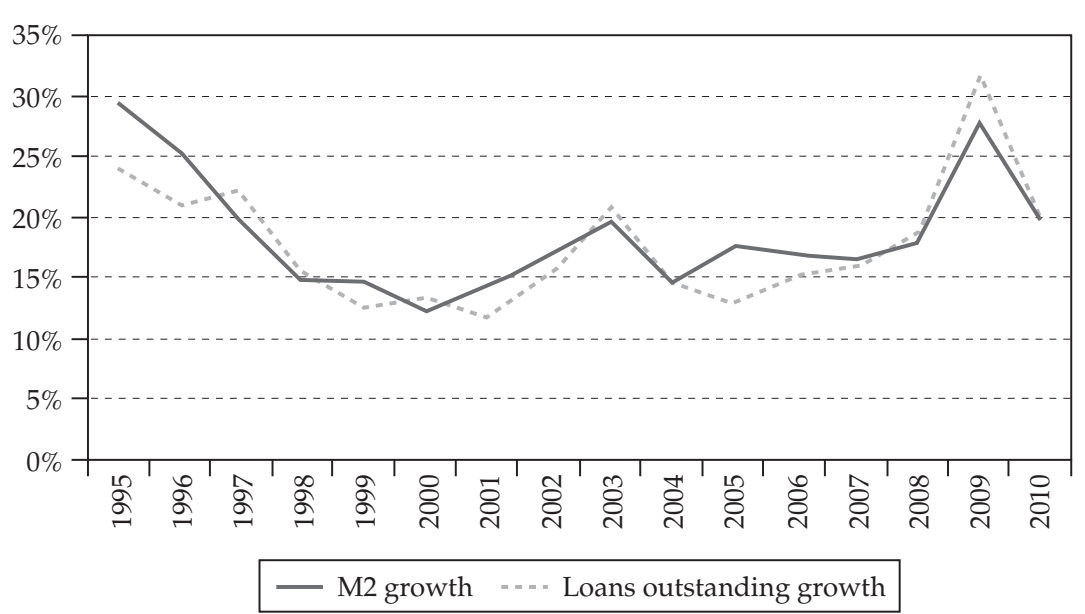

Fuente: Dragonomics.

GRÁFICO 6

CHINA MONEY SUPPLY

(Monthly, yoy \% change)

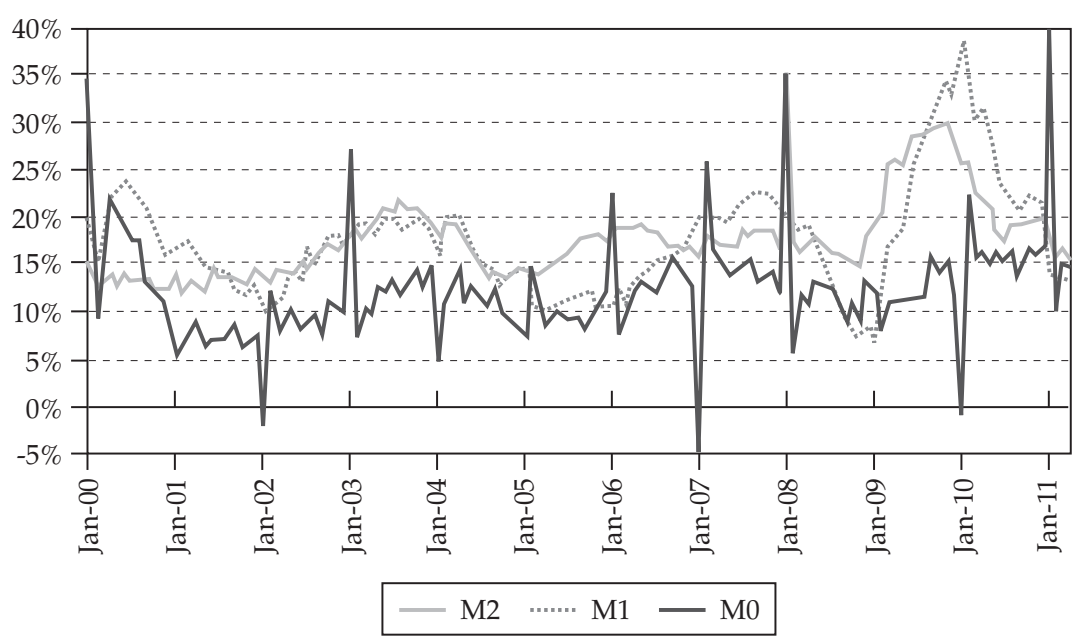

Fuente: Dragonomics. 
GRÁFICO 7

CRECIMIENTO DEL DINERO EN \% ANUAL DE CHINA Y ESTADOS UNIDOS

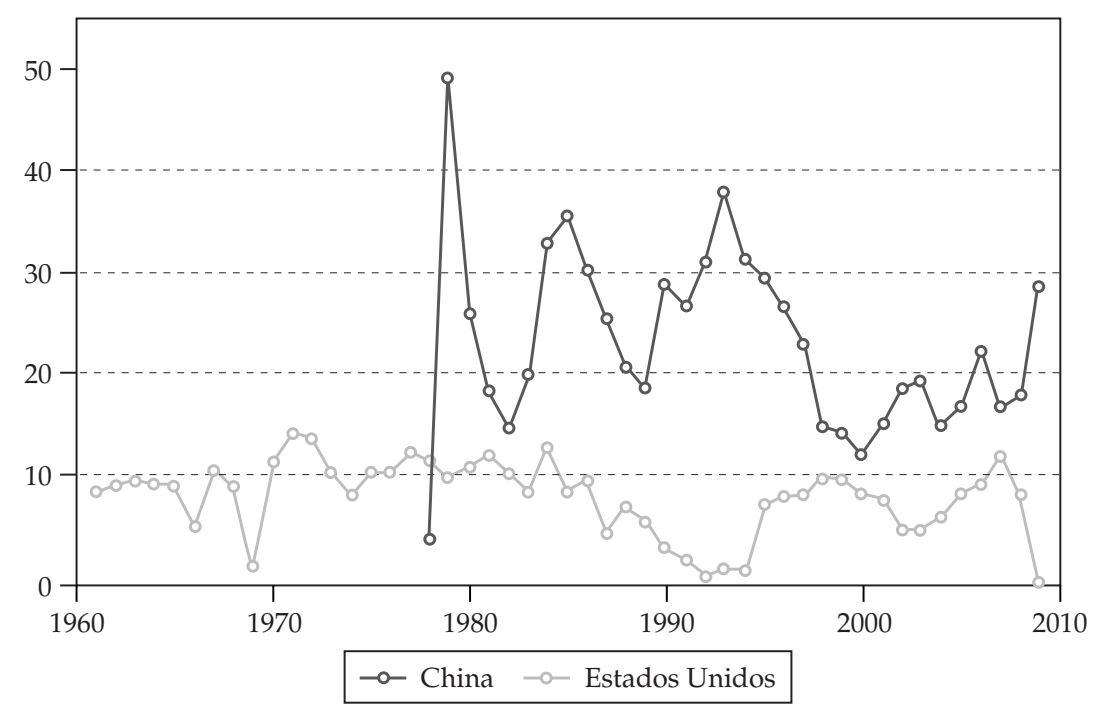

Fuente: Banco Mundial.

¿Cómo podemos saber si esta expansión es artificial o real? Quizá el gráfico de la tasa de ahorro de los hogares lo aclare. El porcentaje de incremento del ahorro de las economías domesticas y en las empresas podemos verlo en el Gráfico 9.

Analizando a partir de 1998, los depósitos de las familias marcaron un máximo de crecimiento en 2003 de un 20\%, para bajar hasta un crecimiento de un 5\% en 2007. Desde entonces los depósitos han crecido hasta un $25 \%$. Como curiosidad, el comportamiento de los depósitos de las familias y de las empresas ha sido similar hasta 2009, donde han invertido sus tendencias, el de las familias a la baja y el de las empresas al alza. ¿Puede ser un síntoma de descoordinación intertemporal debido a la política monetaria? Como «prueba del algodón» comparemos el crecimiento de la masa monetaria y de los depósitos (Gráfico 10).

La evolución de la M0 ha sido justo la contraria a la evolución de los depósitos de los hogares entre 2000 y 2007 y similar a los 
GRÁFICO 8

AHORRO BRUTO INTERNO

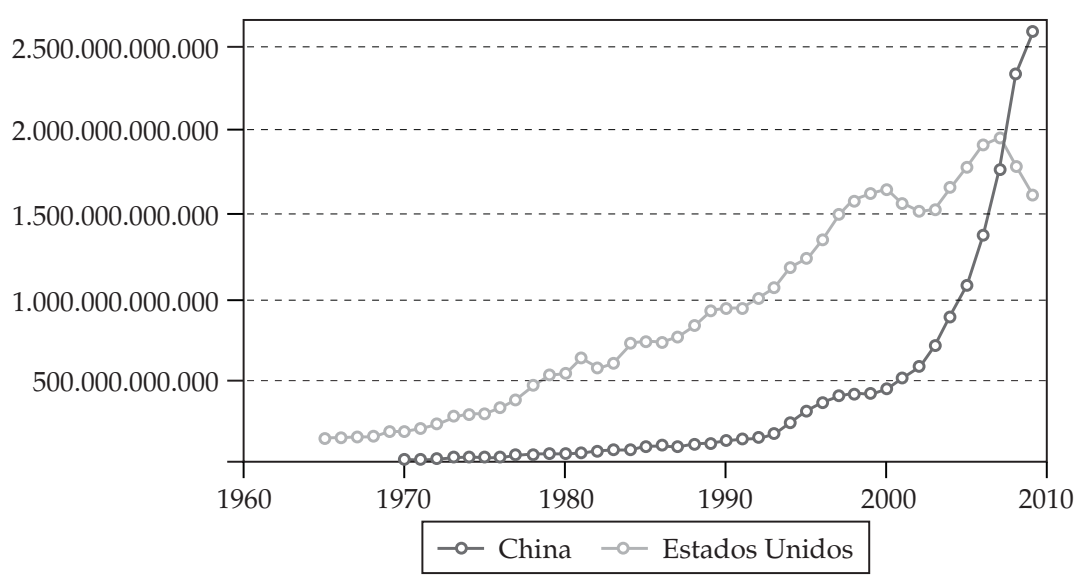

Fuente: Banco Mundial.

GRÁFICO 9

DEPOSITS BY TYPE

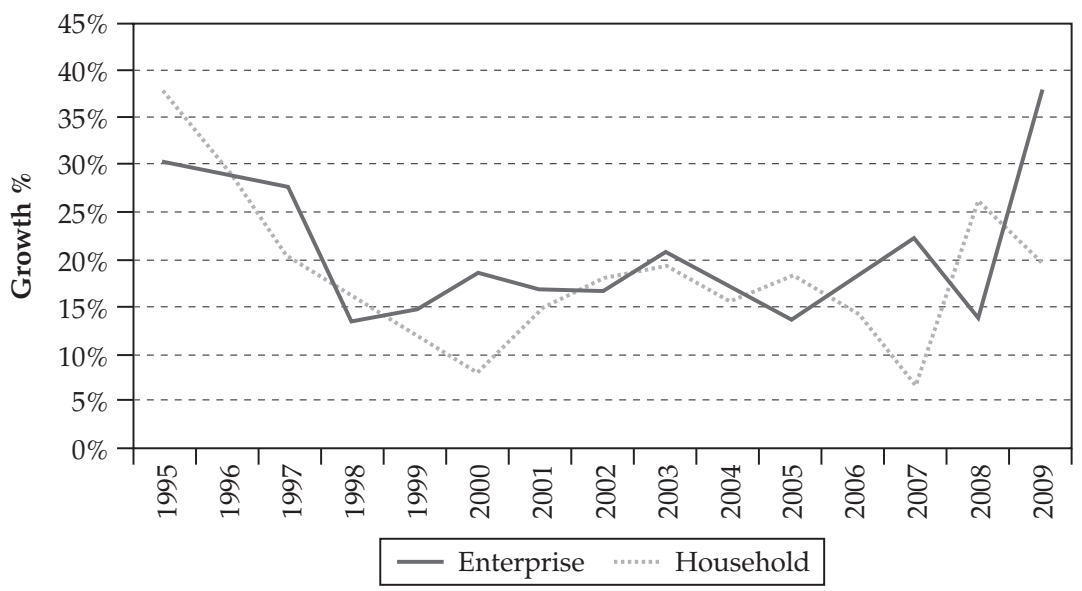

Fuente: Dragonomics.

depósitos de las empresas. Esto parece corroborar que la expansión monetaria ha sido artificial. Veamos la evolución del M2 frente al total de depósitos (Gráfico 11). 
GRÁFICO 10

DEPOSITS BY TYPE VS. MO

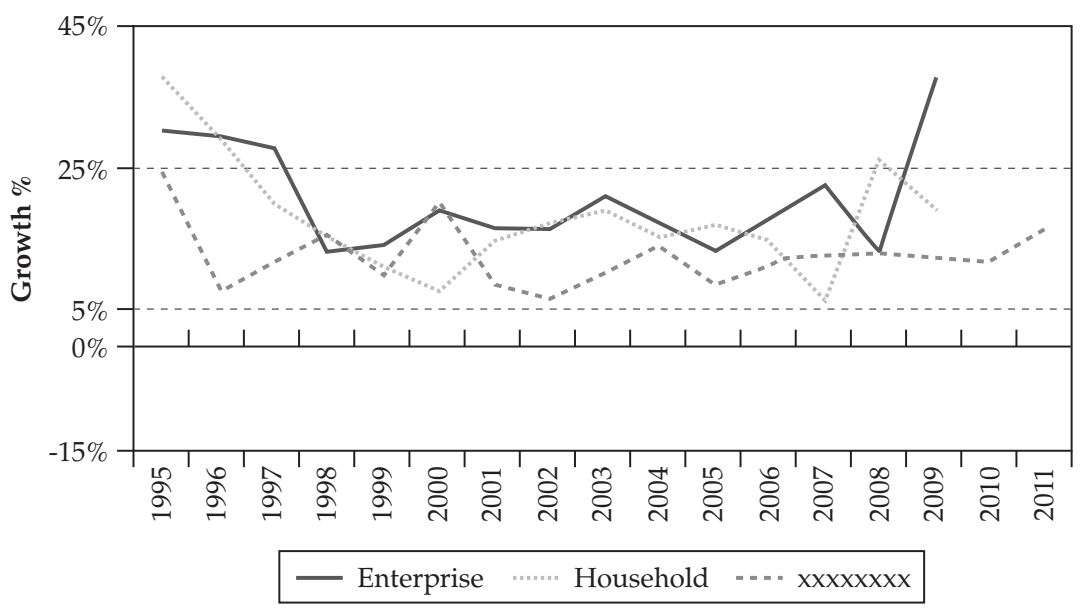

Fuente: Dragonomics.

GRÁFICO 11

\% DEPOSITS VS. M2 GROWTH

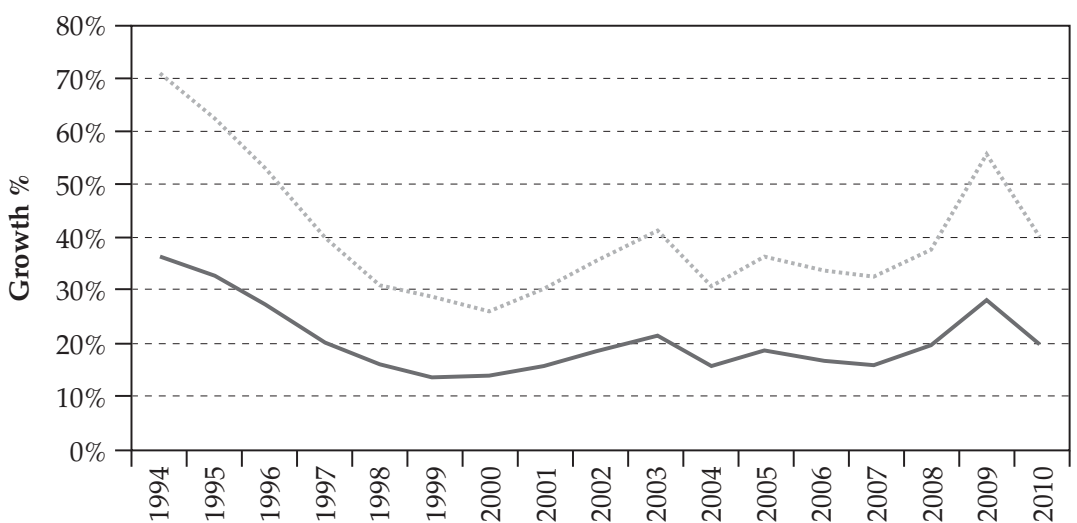

— Deposits of financial institutions growth \% $\quad \ldots \ldots . . .$. M2 \%

Fuente: Dragonomics.

La evolución es muy similar, sin embargo la M2 ha tenido un crecimiento muy superior. 


\section{Tipos de interés}

La expansión de la base monetaria ha tenido como consecuencia una tendencia a disminuir los tipos de interés por debajo de la tasa natural china, pues aunque ésta sea baja, habrá bajado aún más, con lo que ha tenido que disminuir el ahorro y aumentar el consumo. Veamos los datos de la tasa de ahorro, el tipo de interés y del comportamiento de la inversión y del consumo. La evolución del tipo de interés desde 1998 se ve reflejada en el Gráfico 12.

El comportamiento del tipo de interés se ajusta al marco teórico, del 12\% de 1996 al 6\% de 2011 (Gráfico 13).

El tipo de interés al que se prestan los fondos ha descendido desde 1991, aunque ha presentado un suave repunte desde 2002 para volver a bajar a finales de 2008, indicio de inicio de un nuevo ciclo en 2008.

La tasa de interés real China ha sido negativa a mediados de los 90 y ha vuelto a ser negativa en 2003 y 2008. Actualmente presenta una tendencia al alza. Esto ha sido consecuencia de que las autoridades Chinas han estado tratando de poner freno a la inflación.

\section{GRÁFICO 12}

CN: NOMINAL LENDING RATE: SHORT TERM: 1 YEAR

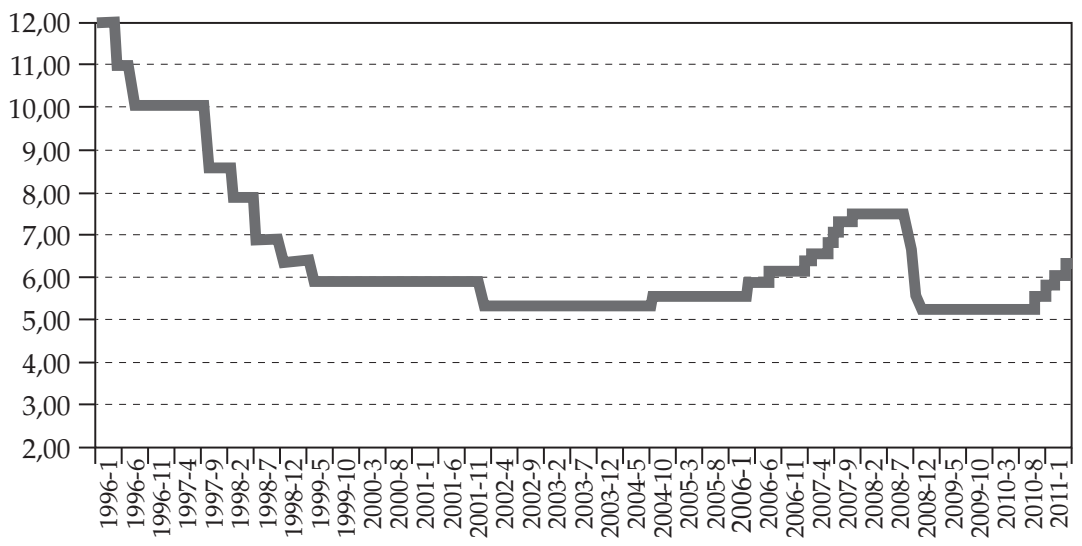

Fuente: Dragonomics. 
GRÁFICO 13

INTEREST RATES

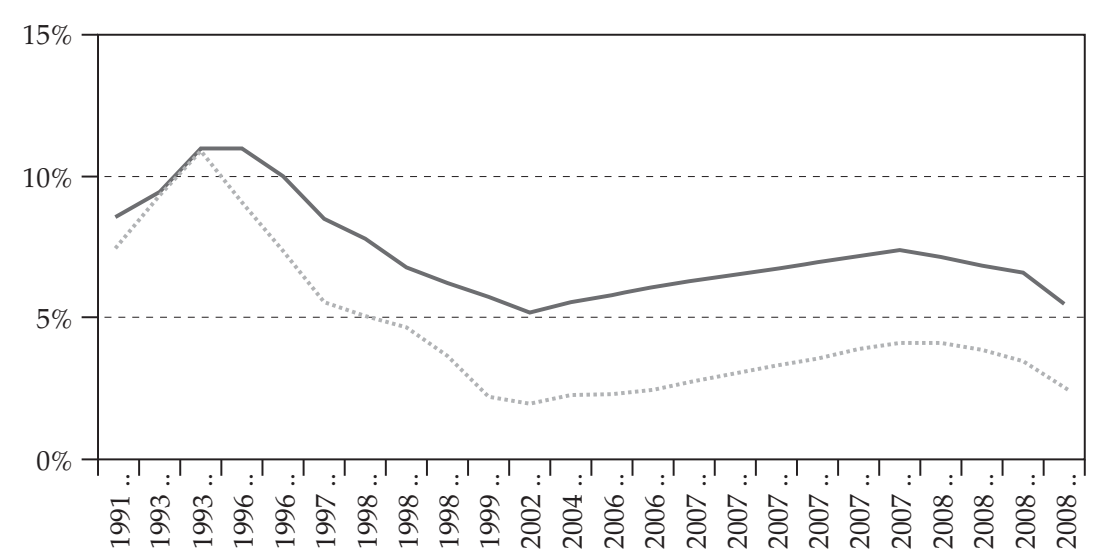

- 1 year loans _en... 1 year savings

Fuente: Dragonomics.

La tasa de interés, comparada con la de Estados Unidos, es similar, excepto a partir de 2009 que invierten sus posiciones, bajista la de USA y alcista la China.

Hay que tener en cuenta la situación de crisis de la economía norteamericana, con los multimillonarios planes de rescate de la Administración Obama. Por el contrario, las autoridades Chinas se están enfrentando en estos momentos a lo que podría ser un cambio de ciclo desde la expansión de 2008 por el aumento de la inflación, casi de un 6,5\% anual en junio de 2011 (Gráficos 14 y 15).

\section{Préstamos y endeudamiento}

¿Cómo se han comportado los agentes ante estos tipos en descenso? Lo podemos saber si vemos la evolución de los préstamos anuales (Gráfico 16).

El volumen de préstamos pendientes ha pasado de los 20.000 billones de yuanes en 2005 a más de 50.000 en 2011 (Gráfico 17). 
GRÁFICO 14

SPREAD BETWEEN ONE YEAR LENDING AND DEPOSITS RATES

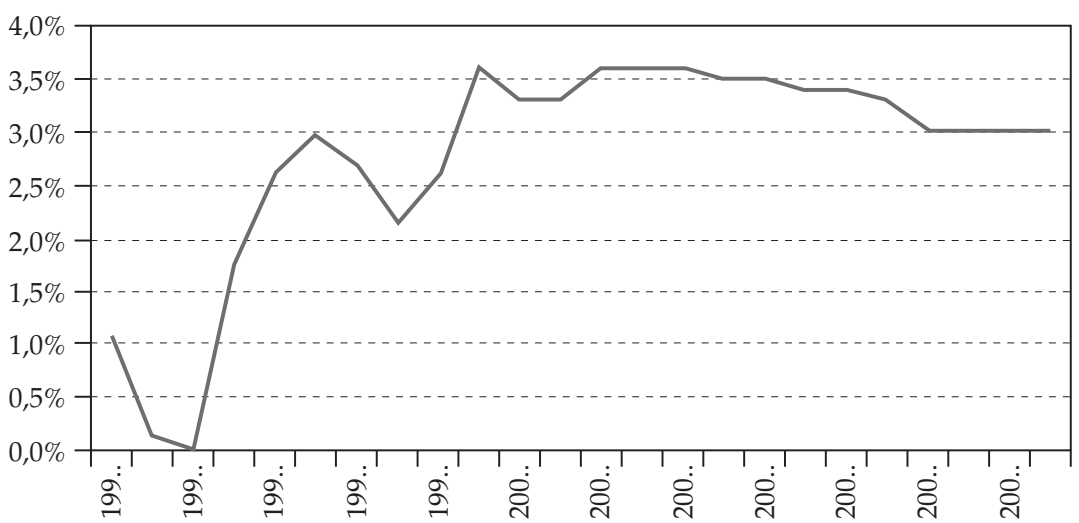

GRÁFICO 15

TASA DE INTERÉS REAL DE ESTADOS UNIDOS Y CHINA

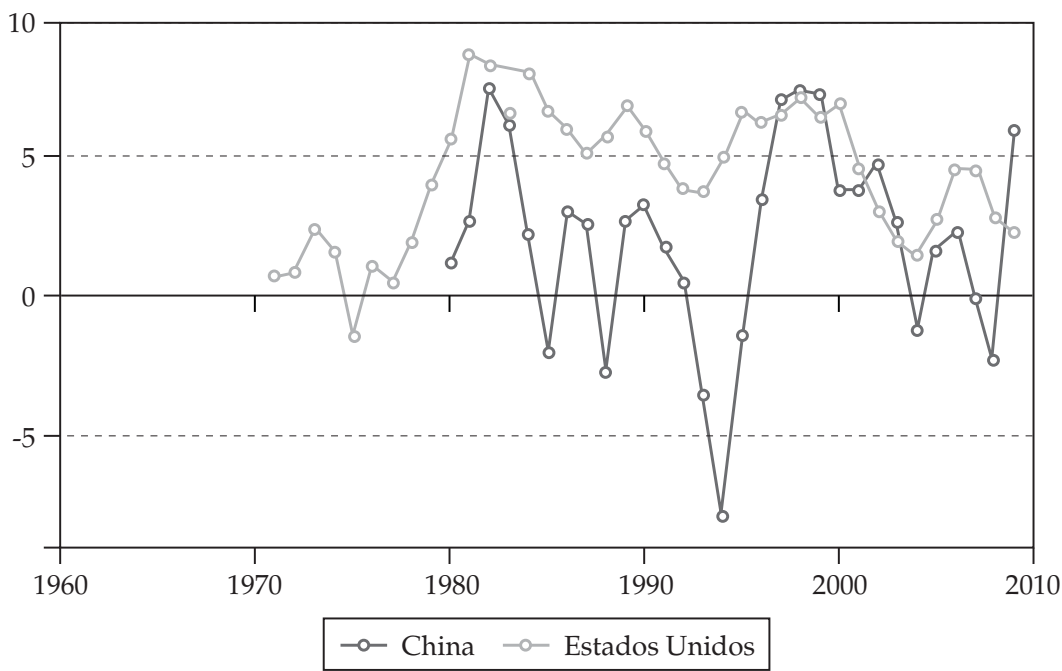

Nota: La tasa de interés real es la tasa de interés activa ajustada por inflación según el deflactor del PIB. Fuente: Fondo Monetario Internacional, Estadísticas Financieras Internacionales y archivos de datos, a partir de datos del Banco Mundial sobre el deflactor del PIB.

Fuente: Indicadores del desarrollo mundial. 
GRÁfICO 16

TOTAL LOANS OUTSTANDING

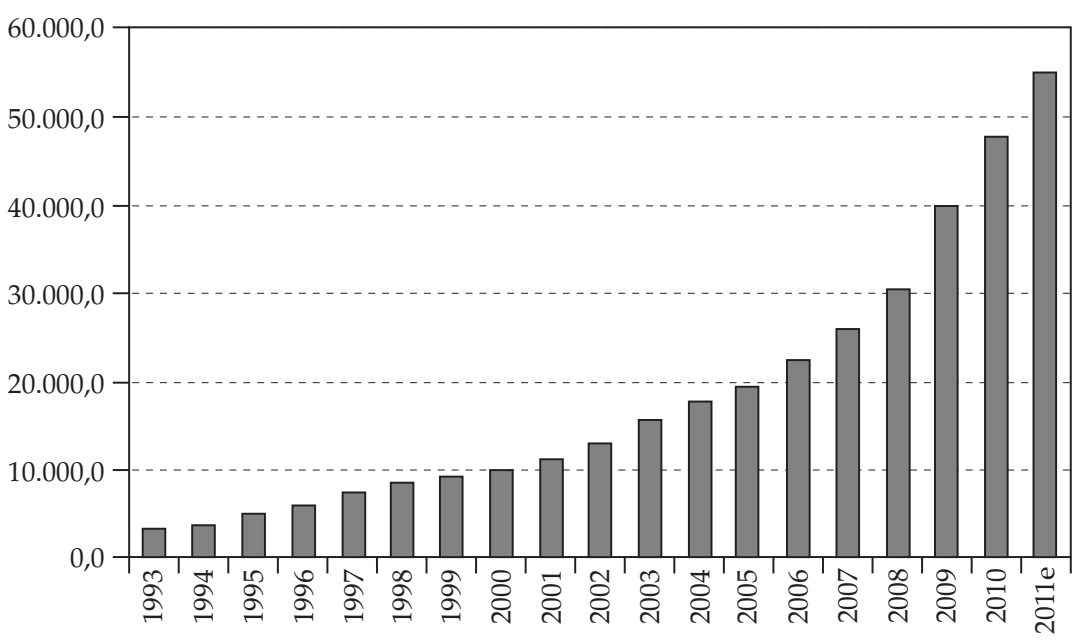

Value Rmb bn

Vemos que los préstamos nuevos han crecido hasta los 10.000 billones de yuanes en 2009, frente a apenas 5.000 millones en 2008 . Esto supone un enorme aumento de los préstamos concedidos en la economía. Lo que podría ser un indicio de ciclo expansivo artificial desde 2008.

La primera conclusión es que la política expansiva de 2008 en materia monetaria (probablemente para paliar lo efectos de la crisis a nivel mundial), está provocando una fase de expansión artificial principalmente en el sector inmobiliario.

\section{Precios}

La manipulación de la masa monetaria, de los tipos de interés y de las facilidades de crédito propiciadas por las autoridades chinas desde 2008, ha de traducirse en tensiones de alza de precios en todos los sectores, tanto en los de las primeras fases de la estructura productiva, mas alejados del consumo, como por ejemplo 
GRÁfICO 17

NEW LOANS

(Annual)

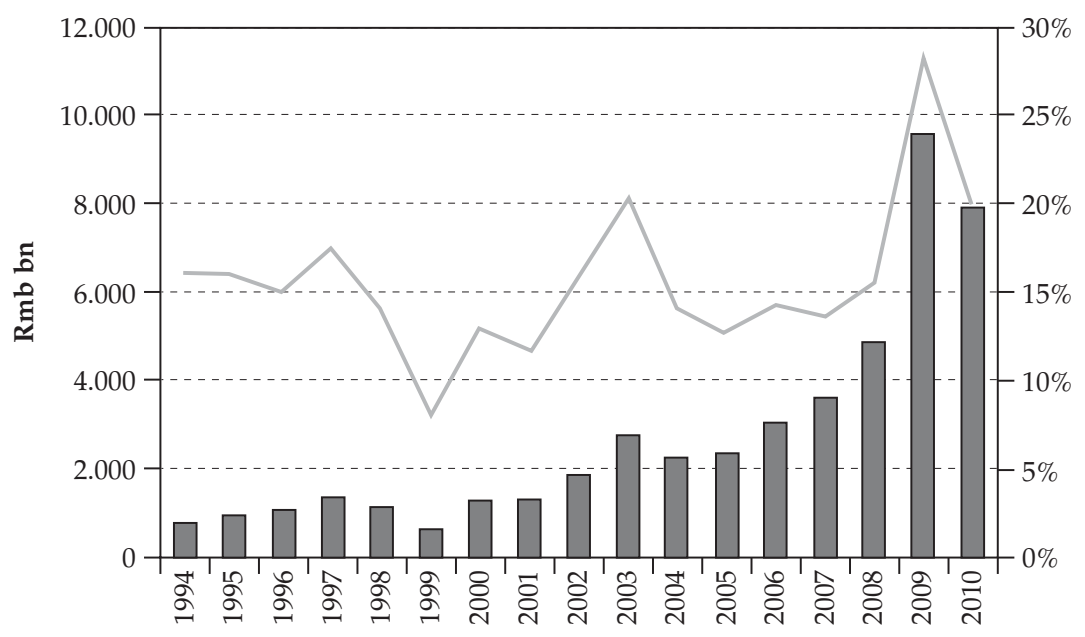

$\square$ New loans (lhs) — New loans as \% of GDP (rhs)

el sector inmobiliario; como en los sectores más próximos al consumo, de los que no se han liberado recursos. El alargamiento de la estructura productiva no responde a estímulos reales, si no a las políticas activas por parte de las autoridades chinas. Veamos gráficamente como se han comportado los precios (Gráficos 18 y 19).

Los índices de precios parecen responder a la política expansiva, desde el descenso de 2008 debido a la crisis mundial, al repunte alcista de todos ellos: de consumo, industriales, de materias primas, inmobiliarios y agrícolas en 2010 (y que continua de forma muy acentuada en 2011) (Gráficos 20 y 21).

En estos momentos, todo apunta a que se esta gestando una «recesión» (o un reajuste) de la economía China que se producirá por la cadena de aumento de precios al consumo, provocándose un incremento de tipos de interés que frenará la expansión en el sector de la construcción, lo que provocara pérdidas en sectores muy dependientes de la construcción: cemento e industria metalúrgica. 
GRÁFICO 18

CONSUMER PRICE INDEX

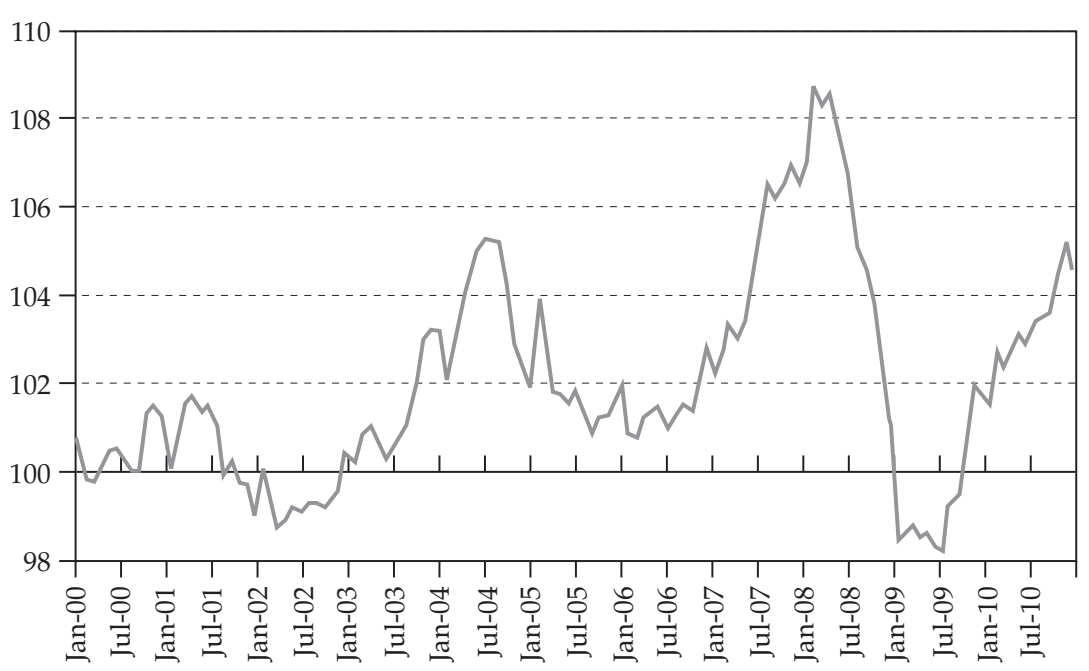

Fuente: Draganomics.

De hecho, ya el Banco Central Chino está procediendo a subir los tipos de interés, como señalaba recientemente una encuesta realizada a un grupo de economistas por el Wall Street Journal. ${ }^{23}$ De la misma opinión es Bod Davis, ${ }^{24}$ colaborador del Wall Street Journal, quién afirma:

Un reciente declive en los precios de los bienes raíces en China genera dudas sobre la vitalidad económica del país y abre el debate sobre si la economía está demasiado apalancada. Eso fue la causa de que el período posterior a la explosión de la burbuja inmobiliaria en Estados Unidos y Japón fuera tan doloroso.

Apenas hace dos meses, Nicholas Lardy, experto en China, desestimó la preocupación sobre lo que denominó «la presunta burbuja de bienes raíces», durante una conferencia en el Instituto Peterson para Economías Internacionales en Washington.

23 http:/ / blogs.wsj.com/chinarealtime/2011/07/07/economists-think-centralbank-is-done-raising-rates-poll/

${ }^{24}$ http://online.wsj.com/article/SB10001424052702304314404576414341091646536. html?mod=WSJS_inicio_MiddleFirst 
GRÁFICO 19

KEY GOODS PRICE INDICES

$(\mathrm{PY}=100)$

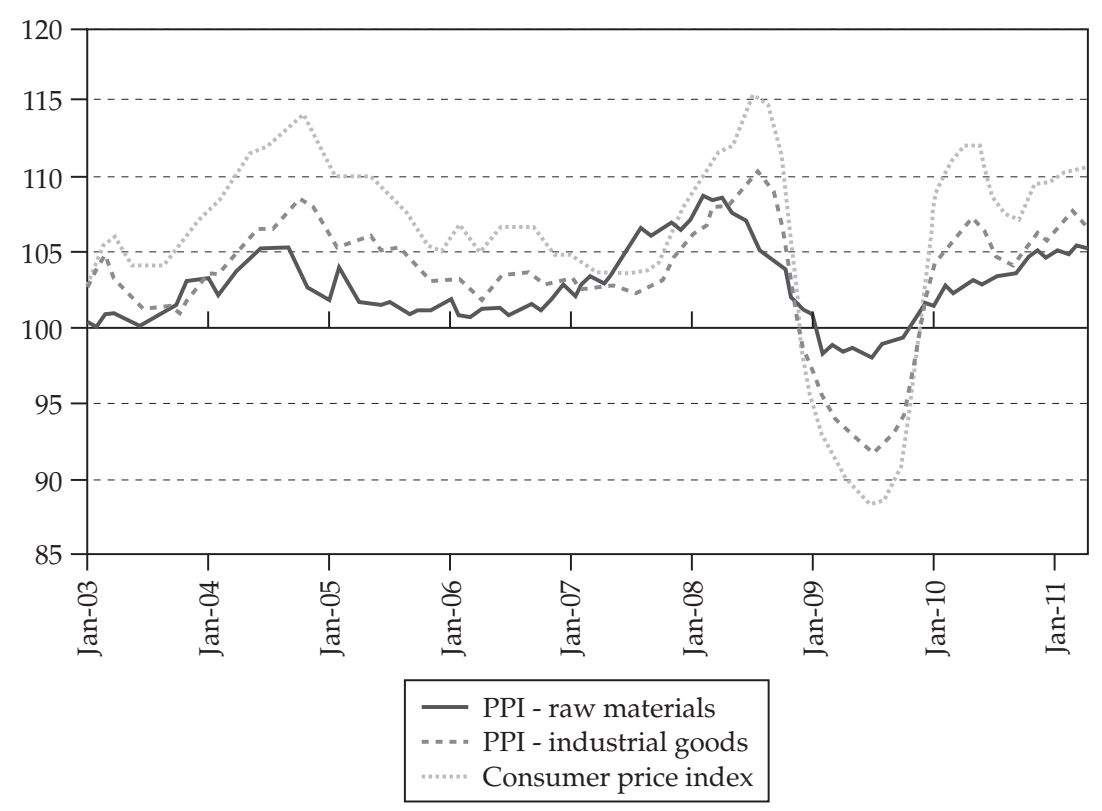

Fuente: Draganomics.

Ahora, dice que un revés en el sector de vivienda podría provocar "una corrección económica muy significativa en China», una opinión compartida por otros economistas.

Para Davis, la causa se encuentra en el aumento del crédito concedido en 2009 y 2010 que se ha utilizado principalmente en la adquisición de terrenos y viviendas. Davis señala: «Entre 2006 y 2010, la inversión en bienes raíces creció un 50\%, llegando a suponer cerca del 9\% del Producto Interno Bruto de China. Durante este lapso, los precios de las propiedades en las principales ciudades chinas casi se duplicaron.»

Hay que señalar que en total, cerca de 50\% del PIB de China está ligado a la suerte de este sector, que representa el 19\% del PIB, calcula Stephen Green, economista de Standard Chartered (Gráfico 22). 
GRÁfICO 20

ASSET PRICE INDICES

$(\mathrm{PY}=100)$

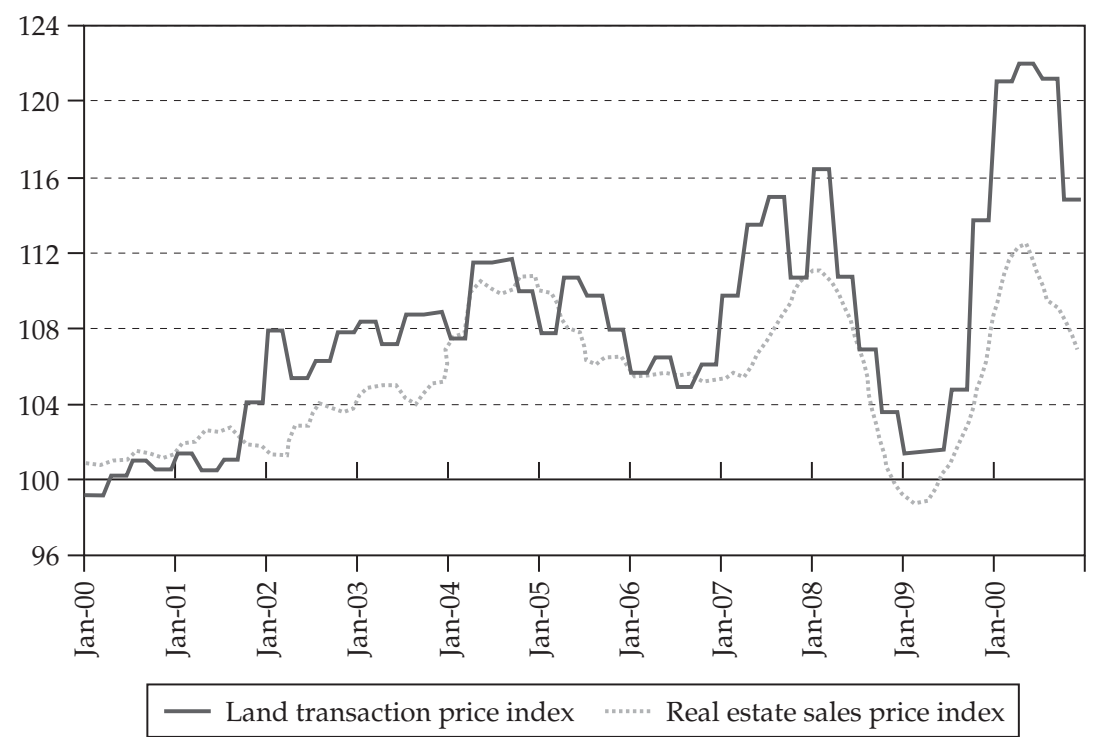

Fuente: Draganomics.

Para algunos no es muy probable que una burbuja inmobiliaria provoque un colapso similar al vivido por USA, Japón o España. Por varias razones:

1. Las autoridades son conscientes de los riesgos de la inflación y la están atacando con firmeza. Las autoridades chinas asientan el poder del partido comunista sobre la estabilidad y bienestar del país. En fechas recientes, en una entrevista concedida al Financial Times, un periodista del medio escribía: «Wen Jiabao afirma que su gobierno ha logrado vencer la inflación en el país con las medidas aplicadas para limitar las subidas de precios».

«Estamos seguros de que los aumentos de precios estarán firmemente controlados este año. El nivel general de precios está en 
GRÁFICO 21

AGRICULTURAL PRICE INDEX

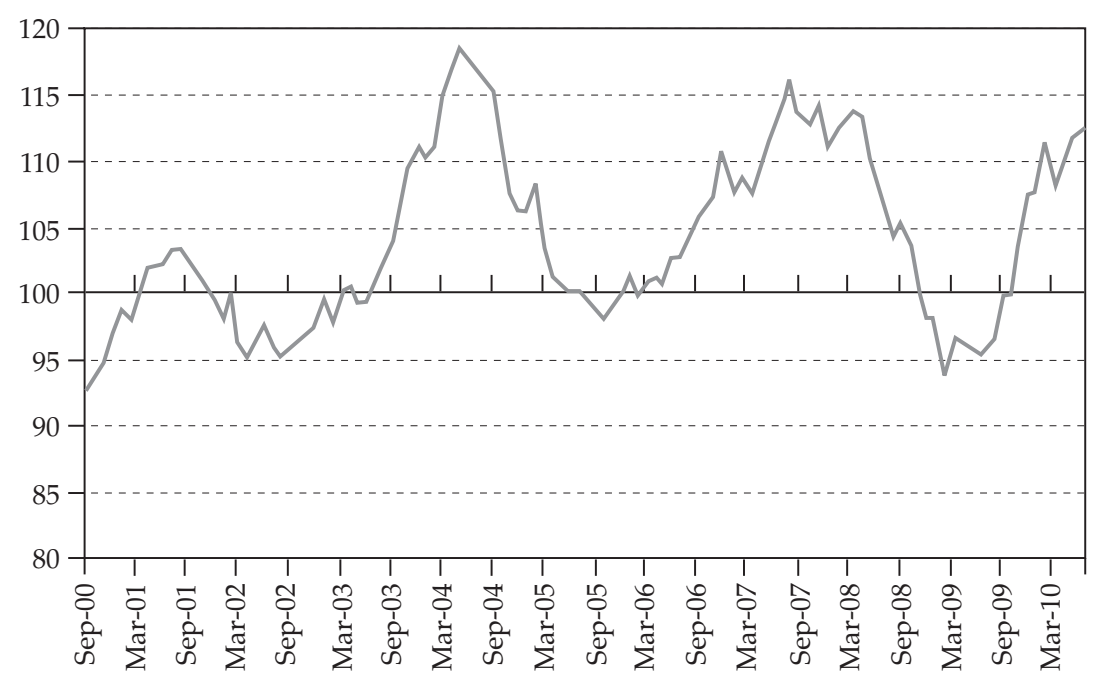

Fuente: Draganomics.

el marco de lo controlable y esperamos que descienda de modo constante», agrega Wen». 25

3. China no está expuesta a las hipotecas subprime que aparecieron en USA en el principio del 2000. Esto no quiere decir que el sistema financiero Chino sea de gran fortaleza, ya que presenta grandes volúmenes de activos de dudoso cobro procedentes de préstamos a empresas estatales con pérdidas.

4. China sigue mostrando una enorme fortaleza exportadora. Como señala Alex Fragos del Wall Street Journal: «La evidencia más reciente del poderío de China se conoció el domingo (3 de julio de 2011) cuando informó que sus exportaciones llegaron a los US\$162.000 millones en junio y a los US $\$ 874.000$

25 http://www.eleconomista.es/economia/noticias/3180655/06/11/Wen-Chinaha-conseguido-vencer-a-la-inflacion.html 
GRÁfICO 22

CONSTRUCTION AS \% OF GDP - CHINA STANDS WELL AHEAD

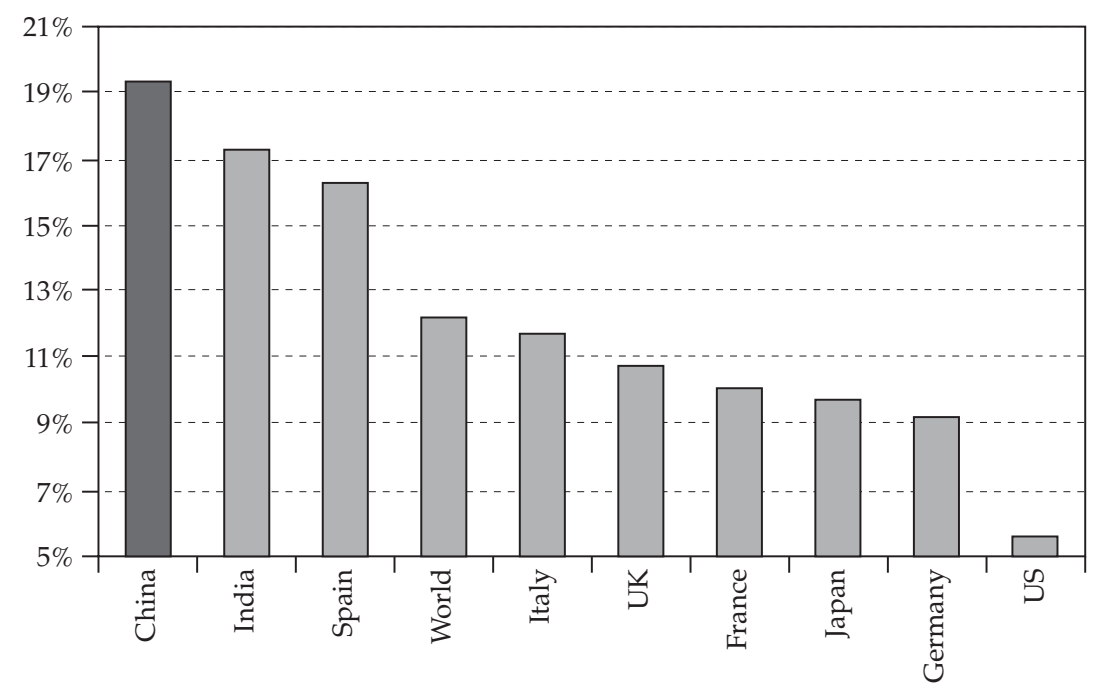

millones en el primer semestre. Ambas cifras son récord y suponen un incremento de casi $20 \%$ con respecto a los mismos lapsos de un año atrás.

No obstante, China se enfrenta actualmente a otros problemas aparte del sector de la construcción: al incremento del precio de las materias primas, de los alimentos y del petróleo. Incluso algunos autores van más allá y sostienen que sin democracia no es posible el avance económico por encima de los 15.000,00 USD de renta per cápita. ${ }^{26}$

${ }^{26}$ http://online.wsj.com/article/SB130592247362617787.html? mod=WSJS mercados_MiddleTop 
IV

\section{CONCLUSIONES}

- La economía china está intervenida y dirigida por las autoridades del país. Según abren o cierran áreas de la economía, el ingente volumen de función empresarial producido por 1.300 millones de personas, da soluciones que escapan a toda imaginación y causan el asombro de los economistas mainstream; no así de los economistas austriacos, familiarizados con el estudio de la acción humana, y que ven en ello el respaldo a la teoría de la función empresarial.

- El enorme grado de control público, unido a la función empresarial ejercida por la población, hace que las respuestas a los estímulos emitidos por las autoridades económicas sea fulgurante y que los ciclos se sucedan de una forma rápida en lapsos de apenas dos o tres años.

- Actualmente la economía china se encuentra en la posición de expansión artificial de la estructura productiva, concentrada principalmente en el sector inmobiliario, producto de los planes de estímulo del 2008. Ya empiezan a evidenciarse los problemas con la aparición de inflación y de sobre-oferta en el sector inmobiliario.

- La producción industrial china sigue marcando récords y parece ajena a la situación, al menos de momento, de exposición del sector inmobiliario.

- Las autoridades ya han tomado medidas urgentes para combatir la inflación, conscientes del peligro que supone para la estabilidad de la economía.

- Con respecto al sector financiero, si la burbuja inmobiliaria fuera severa, podría provocar problemas financieros, si bien no es probable que sean de la magnitud de la crisis sub-prime norteamericana.

- Crisis de divisas: La más que probable devaluación del dólar puede provocar que la pujanza industrial china se vea frenada. Si a esto unimos un pinchazo de la burbuja inmobiliaria, la economía china y por consiguiente la mundial, podría entrar en graves problemas.

- Una crisis severa podría provocar problemas políticos o revueltas similares a las que se han producido en el 2011 en el 
mundo árabe. Las autoridades chinas son conscientes de eso y por tanto, la decisión con la que afrontan los problemas de sus manipulaciones es más enérgica. Al contrario de cómo ocurre en algunos gobiernos occidentales como el español.

China ha emprendido un camino desde 1978 que no va a abandonar. Es más que probable que en 2020 China sea la primera potencia económica mundial a que se paren las reformas. El resto del mundo va a verse beneficiado por la productividad, por un mercado que se abre, y a la vez se va a haber estimulado por la competencia que proporciona la pujanza de la civilización que estuvo a la cabeza mundial durante dos mil años y que vuelve a pedir su sitio en el siglo XXI.

\section{REFERENCIAS BIBLIOGRÁFICAS}

Alonso, Bagus y Rallo (2009): «La crisis Subprime a la luz de la Teoría austriaca del ciclo económico». Publicado en Revista de Economía Mundial 28, 2011.

Garrison, Roger W. (2005): Tiempo y Dinero. La macroeconomía de la estructura de capital. Madrid, 2. ㄹ Edición. Unión Editorial.

HAYEK, F.A. (1996): Precios y producción. Madrid, Unión Editorial. Huerta De Soto, J. (2004): «La teoría Austriaca del ciclo económico». Estudios de Economía Política. Madrid, 2. Edición. Unión Editorial.

- (2005): Socialismo, cálculo económico y función empresarial. Madrid, 3. a Edición. Unión Editorial.

- (2011): Dinero, crédito bancario y ciclos económicos. Madrid, 5. ㄹ Edición. Unión Editorial (1. 르 Edición 1998).

KYNGE, J. (2007): China sacude al mundo. Barcelona, LID Editorial. LeMOINE, F. (2007): La economía china. Madrid, Alianza Editorial. Mises, L. (2005): «La teoría austriaca del ciclo económico». Buenos Aires, Editado por ESEADE. Vol. XII. Revista Libertas.

- (1997): La Teoría del dinero y el crédito. Madrid, Unión Editorial.

- (2007): On the Manipulation of Money and Credit. Auburn, Alabama. Mises Institute. 
Rodríguez Asien, E. (2007): El sistema financiero chino. Madrid, Observatorio de la Economía y la Sociedad de China N.․ํ 01 . Shenkar, O. (2005): El siglo de China. Madrid. Editorial Gránica. Strigl, R. (2007): Capital and Production. Auburn, Alabama. Editado por Mises Institute.

XIABO, W. (2008): La China Emergente. Madrid, Editorial Kailas. 